\title{
Protein Expression of AEBP1, MCM4, and FABP4 Differentiate Osteogenic, Adipogenic, and Mesenchymal Stromal Stem Cells
}

\author{
Thorben Sauer ${ }^{1,+} \oplus$, Giulia Facchinetti ${ }^{1,+},{ }^{+}$Michael Kohl ${ }^{1}$, Justyna M. Kowal ${ }^{2}$, Svitlana Rozanova ${ }^{1}$, Julia Horn ${ }^{1}$, \\ Hagen Schmal ${ }^{3,4}{ }^{\circledR}$, Ivo Kwee ${ }^{5}$, Arndt-Peter Schulz ${ }^{6,7}$, , Sonja Hartwig ${ }^{8,9}{ }^{\circledR}$, Moustapha Kassem ${ }^{2}$, \\ Jens K. Habermann ${ }^{1,10}$ and Timo Gemoll ${ }^{1, *(D)}$
}

Citation: Sauer, T.; Facchinetti, G.; Kohl, M.; Kowal, J.M.; Rozanova, S.; Horn, J.; Schmal, H.; Kwee, I.; Schulz, A.-P.; Hartwig, S.; et al. Protein Expression of AEBP1, MCM4, and FABP4 Differentiate Osteogenic, Adipogenic, and Mesenchymal Stromal Stem Cells. Int. J. Mol. Sci. 2022, 23, 2568. https://doi.org/ $10.3390 /$ ijms 23052568

Academic Editor: C.

Michael Greenlief

Received: 4 February 2022

Accepted: 23 February 2022

Published: 25 February 2022

Publisher's Note: MDPI stays neutral with regard to jurisdictional claims in published maps and institutional affiliations.

Copyright: (C) 2022 by the authors. Licensee MDPI, Basel, Switzerland. This article is an open access article distributed under the terms and conditions of the Creative Commons Attribution (CC BY) license (https:// creativecommons.org/licenses/by/ $4.0 /)$.
1 Section for Translational Surgical Oncology and Biobanking, Department of Surgery, University Hospital Schleswig-Holstein, University of Luebeck, Campus Luebeck, Ratzeburger Allee 160, 23562 Luebeck, Germany; thorben.sauer@student.uni-luebeck.de (T.S.); facchinetti.giuli@gmail.com (G.F.); michael.kohl@uni-luebeck.de (M.K.); svitlana.rozanova@ruhr-uni-bochum.de (S.R.); julia.horn@uni-luebeck.de (J.H.); jens.habermann@uni-luebeck.de (J.K.H.)

2 Department of Endocrinology and Metabolism, University Hospital of Odense, J.B. Winsløws Vej 25, 5230 Odense, Denmark; jkowal@health.sdu.dk (J.M.K.); mkassem@health.sdu.dk (M.K.)

3 Department of Orthopedics and Traumatology, Odense University Hospital, Odense, J.B. Winsløws Vej 4, 5000 Odense, Denmark; hagen.schmal@uniklinik-freiburg.de

4 Department of Orthopedics and Trauma Surgery, Faculty of Medicine, Medical-Center-Albert-Ludwigs-University of Freiburg, Hugstetter Straße 55, 79106 Freiburg, Germany

BigOmics Analytics SA, 6500 Bellinzona, Switzerland; kwee@bigomics.ch

6 Fraunhofer Research Institution for Individualized and Cell-Based Medical Engineering Luebeck, Moenkhofer Weg 239a, 23562 Luebeck, Germany; schulz@biomechatronics.de

7 BG Klinikum Hamburg, Department Centrum Klinische Forschung, Bergedorfer Str. 10, 21033 Hamburg, Germany

8 German Center for Diabetes Research (DZD), 85764 Muenchen, Germany; sonja.hartwig@ddz.de

9 German Diabetes Center, Heinrich Heine University Duesseldorf, Leibniz Center for Diabetes Research, Institute of Clinical Biochemistry and Pathobiochemistry, 40225 Duesseldorf, Germany

10 Interdisciplinary Center for Biobanking-Luebeck, University of Luebeck, Ratzeburger Allee 160, 23562 Luebeck, Germany

* Correspondence: timo.gemoll@uni-luebeck.de; Tel.: +49-451-3101-8703

$+\quad$ These authors contributed equally.

\begin{abstract}
Mesenchymal stem cells (MSCs) gain an increasing focus in the field of regenerative medicine due to their differentiation abilities into chondrocytes, adipocytes, and osteoblastic cells. However, it is apparent that the transformation processes are extremely complex and cause cellular heterogeneity. The study aimed to characterize differences between MSCs and cells after adipogenic $(\mathrm{AD})$ or osteoblastic $(\mathrm{OB})$ differentiation at the proteome level. Comparative proteomic profiling was performed using tandem mass spectrometry in data-independent acquisition mode. Proteins were quantified by deep neural networks in library-free mode and correlated to the Molecular Signature Database (MSigDB) hallmark gene set collections for functional annotation. We analyzed 4108 proteins across all samples, which revealed a distinct clustering between MSCs and cell differentiation states. Protein expression profiling identified activation of the Peroxisome proliferator-activated receptors (PPARs) signaling pathway after AD. In addition, two distinct protein marker panels could be defined for osteoblastic and adipocytic cell lineages. Hereby, overexpression of AEBP1 and MCM4 for OB as well as of FABP4 for AD was detected as the most promising molecular markers. Combination of deep neural network and machine-learning algorithms with data-independent mass spectrometry distinguish MSCs and cell lineages after adipogenic or osteoblastic differentiation. We identified specific proteins as the molecular basis for bone formation, which could be used for regenerative medicine in the future.
\end{abstract}

Keywords: protein profiling; data-independent acquisition mass spectrometry; SWATH; human stromal/mesenchymal stem cells; differentiation markers; machine learning 


\section{Introduction}

Bone marrow stromal cells (MSCs) were first detected by Friedenstein in murine bone marrow cultures [1] and subsequently gained enormous attention regarding their medical utility including cellular therapy applications. MSCs are non-hematopoietic cells originating from the mesodermal germ layer and are detected in a multitude of tissues including bone marrow. Upon tissue migration, MSCs secrete chemokines, cytokines, and growth factors modulating the immune response, angiogenic as well as anti-apoptotic effects [2-5]. MSCs have been proven to be effective treatments in many diseases, e.g., cardiovascular diseases [6,7], musculoskeletal diseases [8], neurological diseases [9], immune system defects $[10,11]$, cancer [12] and tissue regeneration in large bone defects [13-18]. Their clinical efficacy was recently also tested as a therapeutic approach for patients with a COVID-19 infection [19].

In this study, we focus specifically on the characteristics of MSCs in the context of potential treatment interventions in bone lesions. MSCs can differentiate into osteoblasts $(\mathrm{OB})$, adipocytes (AD), chondrocytes and muscle cells [20]. Although the utilization of MSCs as a cellular therapy approach is clinically investigated, the experimental efficacy of MSCs concerning bone regeneration was reported inconsistently regarding the successful in vivo bone formation [18,21-23]. Next to insufficient marker panels for MSC classification, the most likely causes for this observation are cellular and molecular variations of the bone marrow, which does not consist of a homogenous cell type but rather of a population with high cellular heterogeneity containing multipotent stem cells, progenitors and differentiated cells [24-27]. Furthermore, reports suggest that bone marrow contains clonal MSC subpopulations with associations towards either osteoblast or adipocyte lineage. Hence, MSCs show cellular heterogeneity in the context of in vitro osteoblast differentiation, resulting in heterogenous bone formation capacity in vivo [24,28-34] and certain bone diseases such as osteoporosis [35-37].

Since the nature of the MSC differentiation into osteoblasts and adipocytes remains unclear $[23,38,39]$, the specific objective of this study was to characterize undifferentiated MSCs and cells after osteoblastic and adipocytic differentiation on the proteome level. We utilized quantitative mass spectrometry in data-independent acquisition mode combined with machine-learning algorithms for mass spectrometric and statistical evaluation. Generated quantitative proteome data were used to gain further insight into functional annotation including intracellular signaling pathways and gene ontology terms for potential clinical applications. In the future, identified protein candidates for adipocytes or osteoblasts could be used for regenerative therapeutic approaches healing bone fractures or bone diseases.

\section{Results}

\subsection{Cultured Cell Populations Fulfilled Phenotypic Criteria of MSC, Adipocytic and Osteoblastic Criteria}

The individual MSC isolates $(n=5)$, each derived from one single individual (patients p11, p13, p15, p17, and p18), were characterized in vitro (Supplementary Table S1), and have been published elsewhere [32,38]: using a colony-forming unit fibroblast (CFU-F) assay, cultured MSCs formed colonies and expressed alkaline phosphatase (ALP) (median percentage of positive cells $\pm \mathrm{SD}, 37.19 \% \pm 10.91 \%$ ). The cells were further characterized by their MSC surface marker expression recommended by the International Society for Cellular Therapy (ISCT [39]). Cell material of p11, p15, and p18 were limited, wherefore the determination of all surface markers was only possible for $\mathrm{p} 13$ and p17. However, p13 and p17 showed positive expression values for CD44, CD90, CD105 and CD73 in $\geq 99 \%$ (max. SD of $0.16 \%$ ).

After induction of in vitro osteoblastic differentiation, matrix mineralization was visualized by alizarin red staining and compared to cells cultured in control media (Supplementary Figure S1a). Differentiated cells showed a 3.53-fold higher alizarin red intensity after 14 days of culturing. Additionally, cells showed a 6.35-fold higher ALP activity compared to the control cells. Adipocytic differentiation was assessed by quantifying the lipid 
droplet area based on Oil Red O staining after 14 days. All cell cultures showed visible lipid droplets after culturing in adipocyte induction media (Supplementary Figure S1b). These results confirmed the successful differentiation of MSCs into adipocytic and osteoblastic cell types, respectively.

\subsection{Combined Quantitative Mass Spectrometry and Neural-Network-Based Algorithms Revealed} Distinct Protein Expression Patterns of MSCs, Adipocytic and Osteoblastic Cells

To compare differences between adipocyte (AD), osteoblast (OB) lineage cells, and undifferentiated MSCs on the proteome level, we performed microflow ESI-MS/MS analysis using the data-independent acquisition mode for exact quantification. The neuronal network-based workflow of DIA-NN identified 4569 unique proteins (FDR $\leq 0.01$ on both precursor and protein levels). After filtering and imputation of missing values (cf. Section 4.12), quantitative values of 4108 proteins were subsequently compared between groups (AD, OB, and MSCs) to reveal distinct clustering between samples, differentially expressed proteins, and enriched gene sets (cf. Section 4.13). A table containing all protein quantification values is included in Supplementary Table S2.

\subsection{MSCs, Osteoblasts, and Adipocytes Show Distinct Clustering Behavior and Involvement of PPAR}

Phenotypic differences between distinct cell types were visualized using unsupervised principal component analysis (PCA) and hierarchical clustering (so-called 'heatmap') applying detected protein expression data. Both, PCA and hierarchical clustering showed a high discriminating potential and clear separation between the three groups (Figure 1A and Supplementary Figure S2). Analogous to the mass spectrometry-based analysis, twodimensional gel electrophoresis was performed. Here, 1517 protein spots were detected and revealed a similar clustering behavior in the PCA plot (Figure 1B).

In order to identify overrepresented biological states or processes, a gene set enrichment analysis (GSEA) was performed with mass spectrometry derived expression data of all 4108 quantified proteins against the hallmark gene set collection [40]. Nine gene sets were detected as significantly enriched for the OB/AD, three for the OB/MSC, and 10 for the AD/MSC comparison (FDR $<0.05, \mid \log _{2} \mathrm{FCl}>0.2$, Table 1 and Supplementary Figure S3A-C). The most striking result to emerge from the data was the association of both AD comparisons with the hallmark gene set collection 'adipogenesis' which consists of 35 founder gene sets. One of the key signaling pathways for adipogenic differentiation was the 'peroxisome proliferator-activated receptor (PPAR) signaling pathway' which is exemplarily visualized in the Supplementary Figure S4 including the visualized fold changes of the identified proteins for the AD vs. OB comparison: acetyl-CoA acyltransferase 1 (ACAA1), acyl-CoA dehydrogenase medium chain (ACADM), acyl-CoA oxidase 1 (ACOX1), acylCoA synthetase long chain family member 1 (ACSL1), adiponectin, C1Q and collagen domain containing (ADIPOQ), apolipoprotein A1 (APOA1), CD36 molecule (CD36), carnitine palmitoyltransferase 1A (CPT1A), carnitine palmitoyltransferase 2 (CPT2), cytochrome P450 family 27 subfamily A member 1 (CYP27A1), diazepam binding inhibitor, acylCoA binding protein (DBI), enoyl-CoA hydratase and 3-hydroxyacyl CoA dehydrogenase (EHHADH), fatty acid binding protein 4 (FABP4), fatty acid desaturase 2 (FADS2), integrin linked kinase (ILK), lipoprotein lipase (LPL), malic enzyme 1 (ME1), phosphoenolpyruvate carboxykinase 1 (PCK1), perilipin 2 (PLIN2), stearoyl-CoA desaturase (SCD), sterol carrier protein 2 (SCP2), solute carrier family 27 member 4 (SLC27A4), sorbin and SH3 domain containing 1 (SORBS1). With the exception of ILK, all proteins show positive fold-change values indicating a prominent pathway activation. 


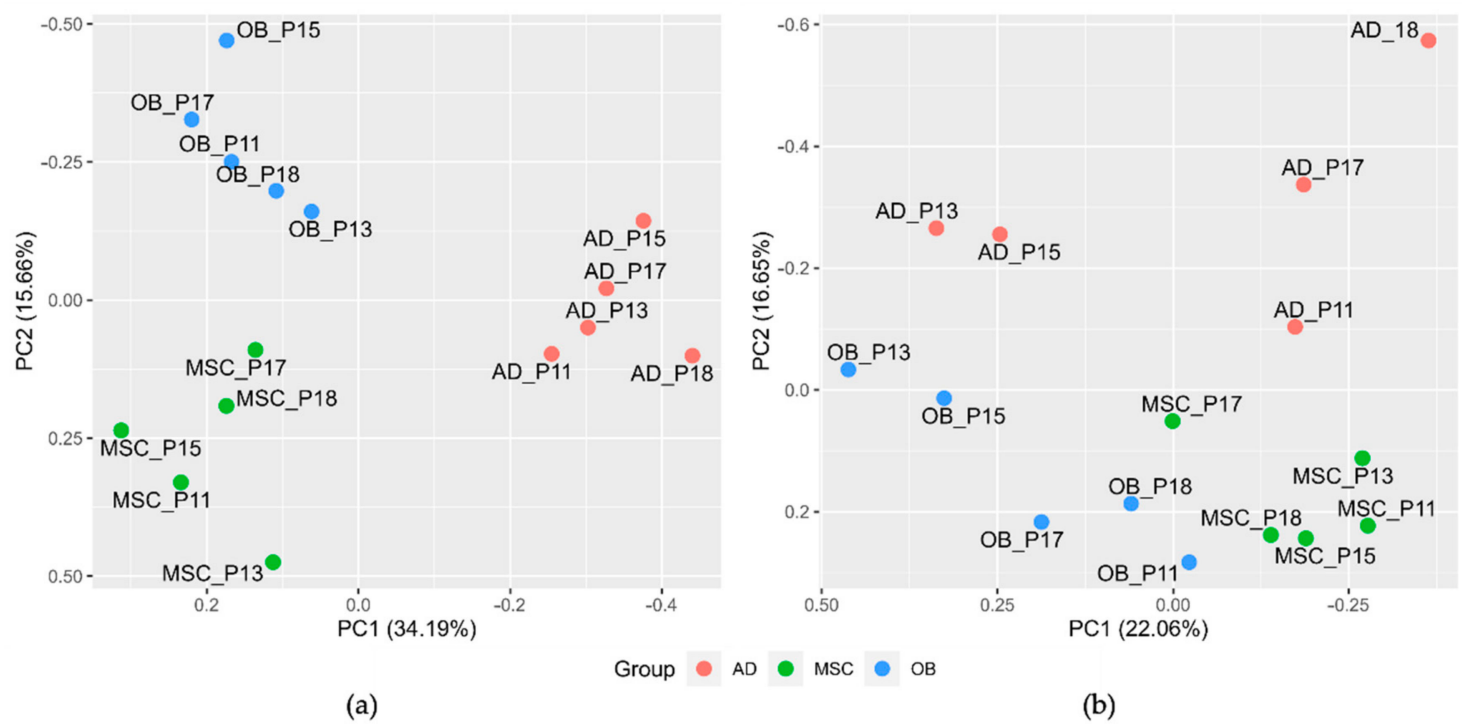

Figure 1. Unsupervised principal component analysis plots derived from mass spectrometry data ((a), 4108 proteins) and two-dimensional gel electrophoresis data ((b), 1517 protein spots). The three cell lineages MSCs (green), OB (blue), AD (pink) were run in quintuples. P11, p13, p15, p17, and p18 indicate the patient number of the corresponding sample. $X$ - and $y$-axes show the first and second principal components, respectively.

Table 1. Enriched gene sets of the MSigDB Hallmark collection for OB versus AD, OB versus MSC, and $\mathrm{AD}$ versus MSC. ( $\log _{2} \mathrm{FC}$, logarithm of fold change; Meta-q, meta $\mathrm{q}$-value used statistical methods; Avg. Expr., average expression).

\begin{tabular}{|c|c|c|c|c|}
\hline Gene set & $\log _{2}$ FC OB vs. AD & Meta-q & Avg. Expr. OB & Avg. Expr. AD \\
\hline MYC_TARGETS_V1 & 0.575 & 0.0005 & 6.103 & 5.528 \\
\hline E2F_TARGETS & 0.410 & 0.0005 & 7.049 & 6.638 \\
\hline G2M_CHECKPOINT & 0.278 & 0.0005 & 5.411 & 5.133 \\
\hline PEROXISOME & -0.223 & 0.0366 & 6.925 & 7.148 \\
\hline BILE_ACID_METABOLISM & -0.317 & 0.0006 & 6.762 & 7.079 \\
\hline FATTY_ACID_METABOLISM & -0.350 & 0.0006 & 6.535 & 6.885 \\
\hline CHOLESTEROL_HOMEOSTASIS & -0.377 & 0.0315 & 6.318 & 6.695 \\
\hline OXIDATIVE_PHOSPHORYLATION & -0.438 & 0.0006 & 5.028 & 5.466 \\
\hline ADIPOGENESIS & -0.491 & 0.0006 & 5.782 & 6.273 \\
\hline Gene set & $\log _{2}$ FC OB vs. MSC & Meta-q & Avg. Expr. OB & Avg. Expr. MSC \\
\hline MYC_TARGETS_V2 & 0.279 & 0.0435 & 5.745 & 5.466 \\
\hline E2F_TARGETS & 0.274 & 0.0008 & 7.034 & 6.76 \\
\hline MYC_TARGETS_V1 & 0.241 & 0.0098 & 6.076 & 5.835 \\
\hline Gene set & $\log _{2}$ FC AD vs. MSC & Meta-q & Avg. Expr. AD & Avg. Expr. MSC \\
\hline OXIDATIVE_PHOSPHORYLATION & 0.659 & 0.0006 & 5.590 & 4.931 \\
\hline CHOLESTEROL_HOMEOSTASIS & 0.533 & 0.0006 & 6.654 & 6.121 \\
\hline ADIPOGEENESIS & 0.529 & 0.0006 & 6.206 & 5.677 \\
\hline FATTY_ACID_METABOLISM & 0.478 & 0.0006 & 6.909 & 6.431 \\
\hline BILE_ACID_METABOLISM & 0.411 & 0.0006 & 7.096 & 6.685 \\
\hline PEROXISOME & 0.337 & 0.0028 & 7.282 & 6.945 \\
\hline XENOBIOTIC_METABOLISM & 0.271 & 0.0011 & 5.857 & 5.585 \\
\hline PI3K_AKT_MTOR_SIGNALING & -0.203 & 0.0359 & 7.127 & 7.331 \\
\hline MYC_TARGETS_V1 & -0.334 & 0.0105 & 5.605 & 5.939 \\
\hline MITOTIC_SPINDLEE & -0.335 & 0.0006 & 6.635 & 6.97 \\
\hline
\end{tabular}




\subsection{Discovery of Differentially Expressed Proteins}

For the detection of differentially expressed proteins, all three two-group comparisons were carried out using an ANOVA with Benjamini-Hochberg correction and Tukey post hoc testing (Supplementary Table S3). While the comparison between OB and MSCs identified 50 differentially expressed proteins (post-hoc q-value $<0.05, \mid \log _{2} \mathrm{FCl}>2$ ) with 25 proteins being over- and under-expressed in the OB group, respectively (Figure 2a), the comparison $\mathrm{OB}$ versus AD revealed 66 proteins with differential abundance (16 over- and 50 under-expressed in the OB group, Figure $2 \mathrm{~b}$ ). The evaluation between AD and MSC revealed 61 proteins with a higher and 25 with lower protein abundance ( 86 differential expressed proteins in total, Figure 2c).

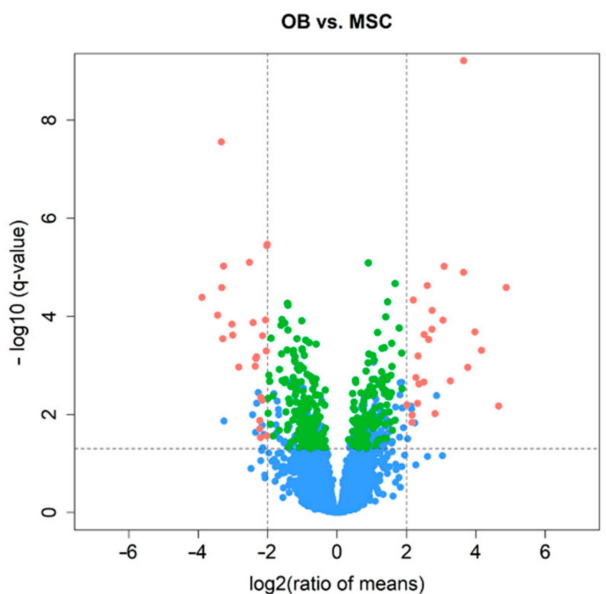

(a)



(c)

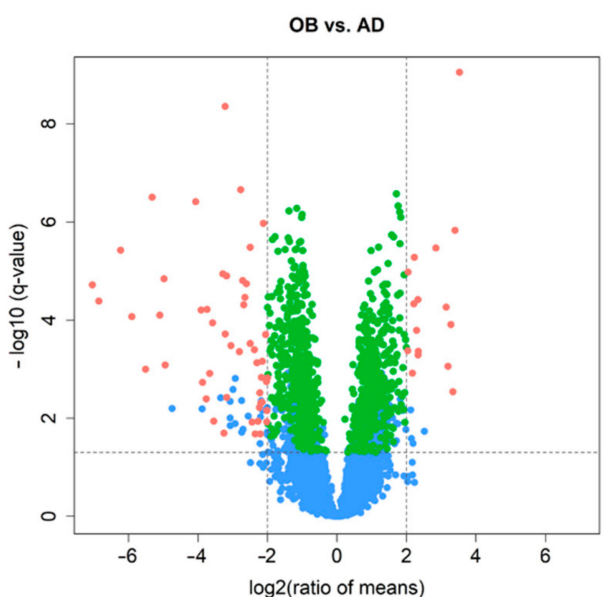

(b)

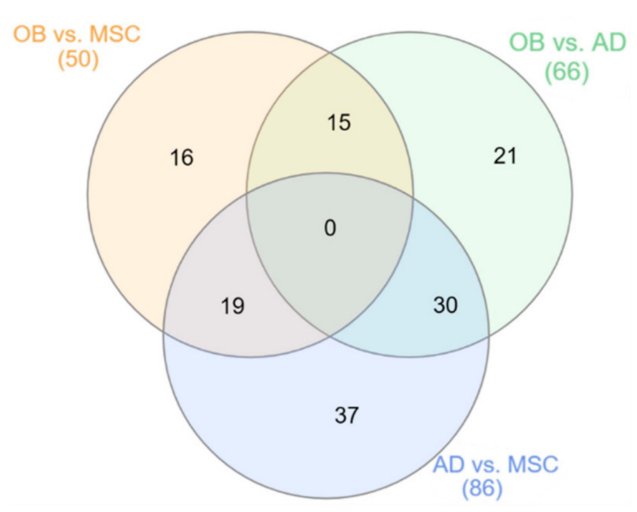

(d)

Figure 2. Volcano plots of differentially expressed proteins between MSCs, osteoblasts, and adipocytes $(\mathbf{a}-\mathbf{c})$ as well as a Venn diagram indicating the overlap of differentially abundant proteins between all three group comparisons (d). Volcano plots are presented with the fold-change of the corresponding comparison in logarithmic scale ( $x$-axis) against the q-value of the Tukey's post hoc test ( $y$-axis). Significance thresholds (q-value $<0.05$ and $\mid \log _{2} \mathrm{FCl}$ threshold of $>2$ ) are indicated by dashed lines. Proteins passing these cut-offs are considered significant and colored in pink. Proteins passing the ANOVA and post-hoc q-value but not the $\log _{2} \mathrm{FC}$ threshold are colored in green. Proteins that were not significant in the ANOVA but in Tukey's post hoc are indicated in blue. (a) OB vs. MSC comparison, 50 proteins are identified as significantly differentially expressed. (b) OB vs. AD comparison, 66 proteins are identified as significantly differentially expressed. (c) AD vs. MSC comparison, 86 proteins are identified as significantly differentially expressed. (d) Venn diagram indicating the overlap of differentially abundant proteins (ANOVA) of all three defined comparisons. 


\subsection{Two Distinct Protein Panels Differentiate Osteoblasts and Adipocytes from Mesenchymal Stem Cells}

Next, the separation of the three distinct cell types based on their protein expression profiles was analyzed. In total, 15 proteins which were both identified as differentially expressed in the OB vs. MSC and OB vs. AD comparison were defined as osteoblastspecific proteins. In analogy, 30 proteins that were differentially expressed in the AD vs. MSC and OB vs. AD comparison were defined as adipocyte-specific proteins (Figure 2d). To validate the results of the ANOVA analysis, expression data were further evaluated by computing their variable importance using machine learning algorithms (LASSO [41], elastic nets [42], random forests [43], and extreme gradient boosting [44]): the results confirmed 9 out of 15 proteins (60\%) for the osteoblastic and 13 out of 30 proteins (43\%) for the adipocytic panel.

\subsubsection{Osteoblastic Panel}

A total of nine differentially expressed proteins were calculated combining two feature selection approaches (classical statistical analysis and machine learning algorithms) for the osteoblastic panel showing six (66\%, AEBP1, BGN, CARMIL1, CYP24A1, MCM4, STMN1) with a higher and three (33\%, COL3A1, MEST, P4HA1) with lower expression in the osteoblastic group. Expression levels of these nine osteoblast-specific proteins are visualized in Figure 3a. Closer inspection of the figure showed a protein expression of AEBP1 and MCM4 in the AD and MSC group with uniformly low expression values (range of means: 1.09-1.60) and coefficients of variation (CV, range: $0.28-0.64)$.

\subsubsection{Adipocytic Panel}

For the adipocytic panel, a total of 13 differentially expressed proteins (ACSL1, CD36, EPHX1, FABP4, HP, HSD11B1, ITIH1, MAOA, PLIN1, PLIN4, PLPP1, RAP2A, SCD) were detected all being more highly expressed in the AD group. Expression levels of these 13 adipocyte-specific proteins are visualized in Figure 3b. It is apparent from this figure that the protein expression of FABP4, ITIH1, SCD, PLIN1, and PLIN4 in the OB and MSC group presented uniformly low expression values (range of means: $0.24-1.04$ ) and coefficients of variation $(\mathrm{CV}$, range: $0.36-1.72)$.

As a summary, differentially expressed proteins which were cell-type specifically differentially expressed and further validated by the machine learning strategies are presented as a heatmap in Figure 4 and Supplementary Table S4 including gene symbols, UniProt IDs, descriptive statistics, ANOVA with post-hoc results, fold changes and functional GO-term annotations. 

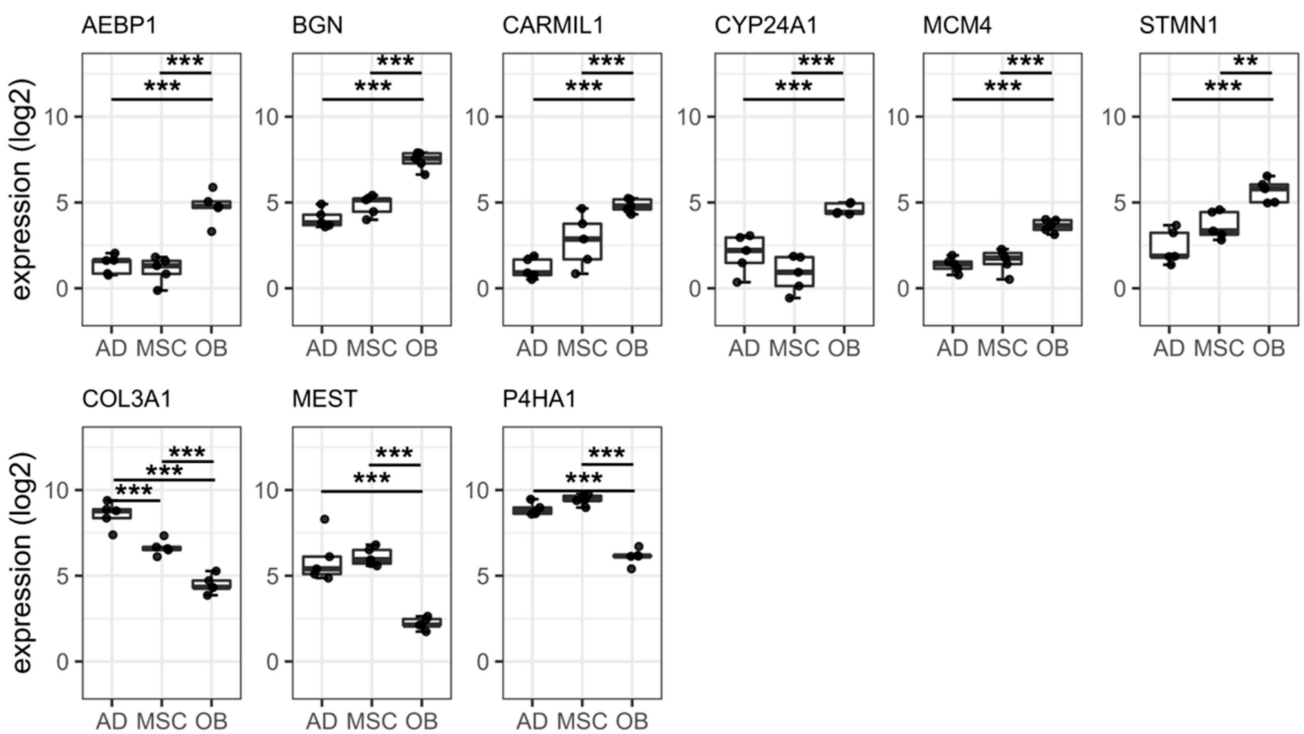

P4HA1

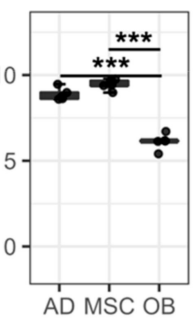

(a)
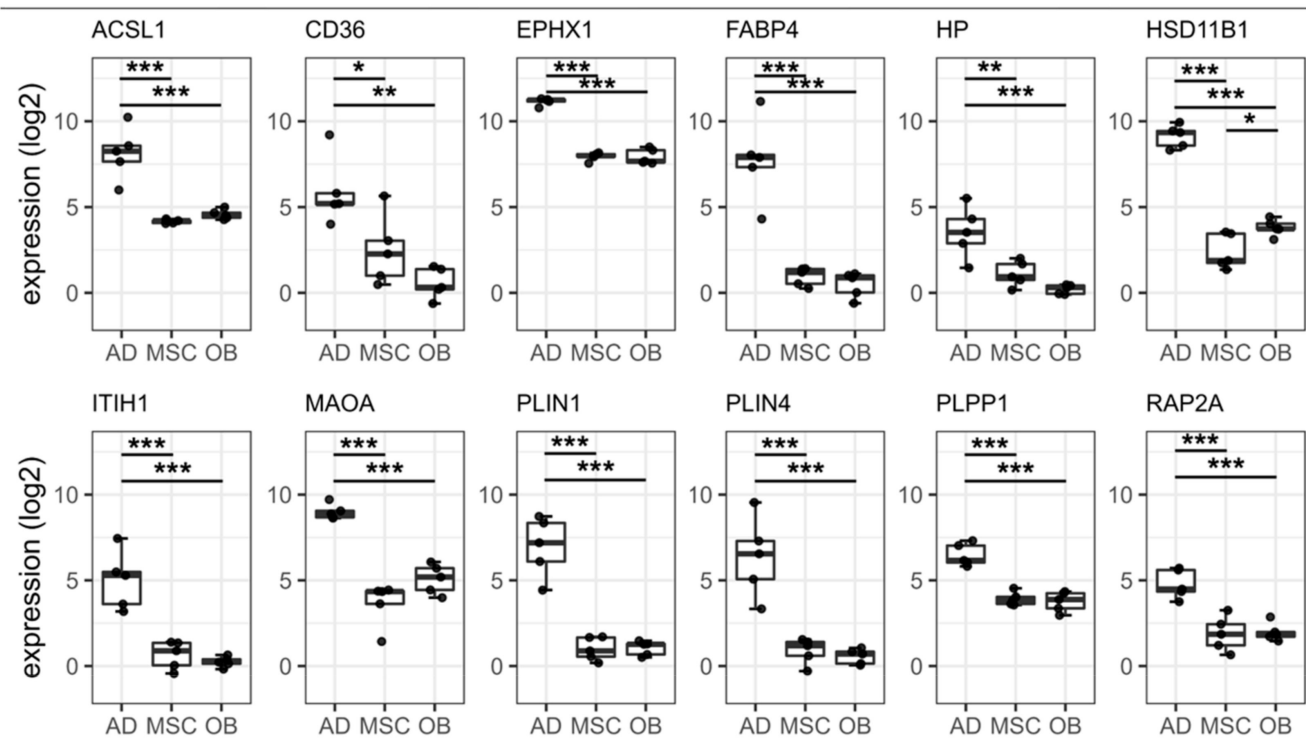

PLIN1

PLIN4
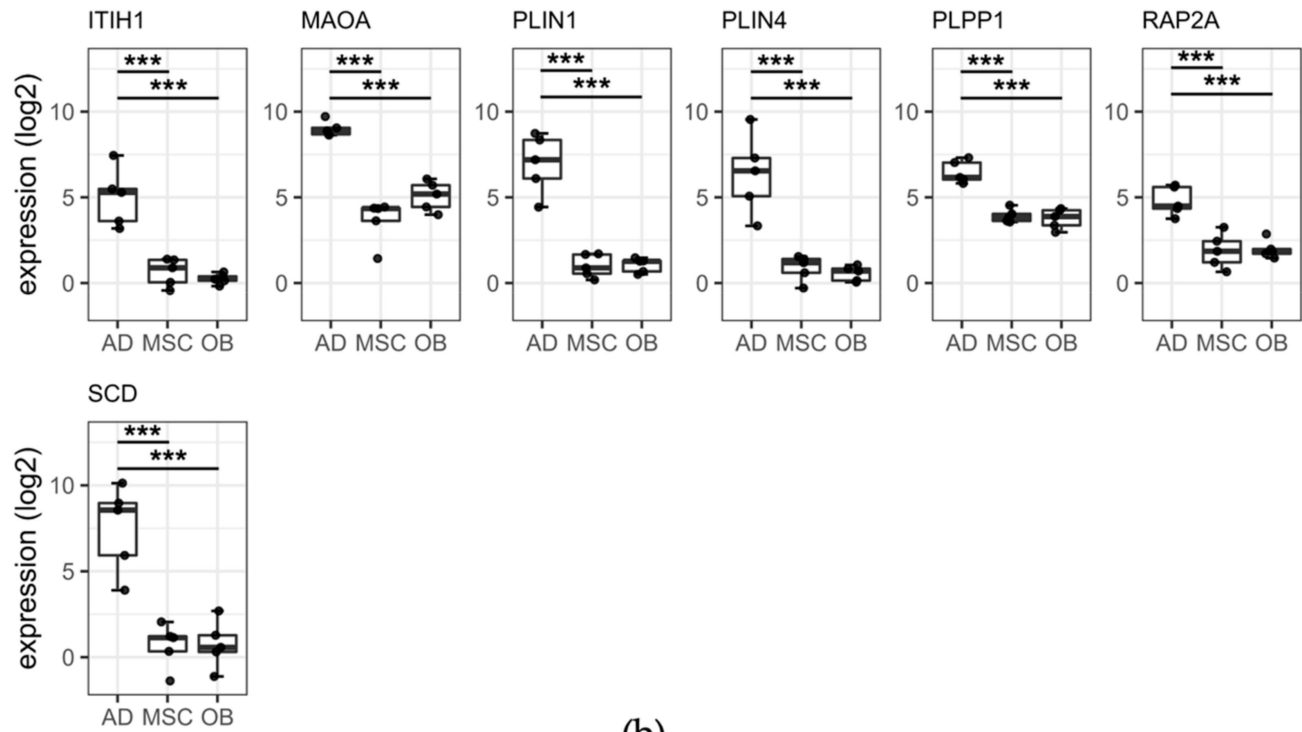

(b)

Figure 3. Boxplots of nine proteins for (a) osteoblastic differentiation and (b) adipocytic differentiation using ANOVA and machine learning algorithms. Individual data points are shown with median expression in $\log _{2}$ of the measured intensity. Whiskers are plotted according to the Tukey method indicating $1.5 *$ interquartile range. The osteoblastic protein (a) COL3A1 and the adipocytic protein (b) HSD11B1 show significant differential expressions for all three comparisons (indicated by asterisks), however, the comparison between the AD and MSC group and OB and MSC did not exceed the net $\log _{2}$ FC threshold of 2, respectively. Asterisks indicate the Tukey's post hoc q-value results: ${ }^{*}=\leq 0.05$, ${ }^{* *}=\leq 0.01,{ }^{* * *}=\leq 0.001$. 
$\mathrm{OB}$
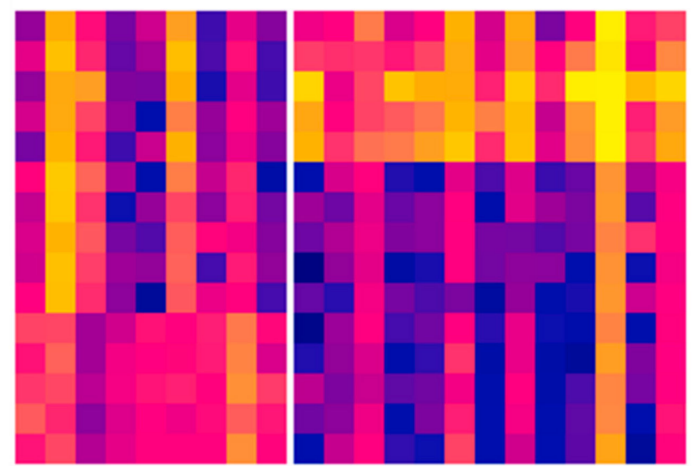

AD P11

$A D$ P13

AD P15

$A D P 17$

AD_P18

MSC P11

MSC_P13

MSC_P15

MSC P17

MSC_P18

OB_P11

$\mathrm{OB} P 13$

OB_P15

OB_P17

OB P18

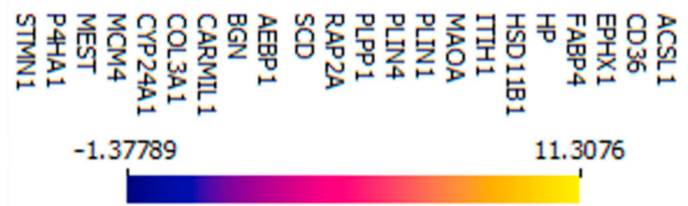

Figure 4. Heatmap of 22 marker proteins for osteoblastic and adipocytic differentiation. Expression values are shown in $\log _{2}$ of the measured intensity.

\subsection{MSC Marker Protein Panel Comparison}

The Mesenchymal Tissue Stem Cell Committee of the International Society of Cellular Therapy (ISCT) defined a set of cluster differentiation (CD) cell surface markers for MSC classification (CD105+, CD73+, CD90+, CD45-, CD34-, CD14-, CD11b-, CD79a- or CD19and HLA-DR-). However, reports suggest that this marker panel is insufficient to distinguish undifferentiated MSCs from differentiated adipocytes or osteoblasts [32,38]. This inconsistency is also supported by our quantitative protein data shown in Table 2. It is apparent from this table that all ISCT-defined markers identified showed no significance across comparisons. Additionally, CD90 was the only protein to present a net $\log _{2}$ fold change $>1.0$ (OB vs. MSC comparison). All CD markers that are defined by a very low protein level by the ISCT were not identified in the analyzed samples.

Table 2. Protein expression values of CD markers that have been defined by the International Society of Cellular Therapy for MSC classification. (+) defined high protein expression in MSCs; (-) defined low expression in MSCs. (CV, coefficients of variation; q-value, adjusted post-hoc $p$-value; $\log _{2}$ FC, logarithm of fold change).

\begin{tabular}{ccccccc}
\hline Protein & Gene Name & CV & q-Value & $\begin{array}{c}\text { Log }_{2} \text { FC } \\
\text { AD vs. MSC }\end{array}$ & $\begin{array}{c}\mathbf{L o g}_{2} \text { FC } \\
\text { OB vs. MSC }\end{array}$ & $\begin{array}{c}\text { Log }_{2} \text { FC } \\
\text { OB vs. AD }\end{array}$ \\
\hline CD105+ & ENG & 0.104 & 0.25 & 0.121 & -0.884 & -0.763 \\
CD73+ & NT5E & 0.064 & 0.43 & 0.426 & 0.157 & -1.046 \\
CD90+ & THY1 & 0.121 & 0.41 & 0.355 & Not Identified & -0.691 \\
CD45- & PTPRC & & & Not Identified & Not Identified \\
CD34- & CD34 & & & Not Identified & Not Identified \\
CD14- & CD14 & & & Not Identified & \\
CD11b- & ITGAM & & & Not Identified \\
CD79a- & CD79a & & &
\end{tabular}

\section{Discussion}

Therapy development for bone regeneration is highly challenging and depends on the in vitro differentiation of MSCs into favorable bone-forming osteoblasts. It has been shown that, e.g., osteoblast-like cells derived from MSCs can prevent glucocorticoid-induced bone 
loss [45] and support bone regeneration [46]. However, the prediction of MSCs to differentiate into osteoblasts is hampered by the incomplete biomolecular understanding and the lack of cellular biomarkers that define the quality of cells designated for therapy [29]. The present study was designed to determine differences between MSCs and their differentiated adipocytes (AD) and osteoblasts (OD) on the proteome level. Although previous studies evaluated the relationship between MSCs and osteoblasts using proteomics approaches such as mass spectrometry [47-50], this is the first report comparing the global proteome of MSCs, osteoblasts, and adipocytes by using label-free mass spectrometry in data-independent acquisition mode for quantification. Additionally, updated workflows for machine learning algorithms were applied for in-depth protein identification and data evaluation.

Cluster analysis of proteomics data indicated a clear separation of all cell types along with an enrichment of hallmark gene sets, e.g., associated with adipogenesis including, e.g., PPAR (Peroxisome proliferator-activated receptors) signaling gene sets which is considered as the key master transcription regulator in adipocytes [51]. The Mesenchymal and Tissue Stem Cell Committee of the International Society for Cellular Therapy (ISCT) has defined MSC by a set of present (+) and absent (-) cluster of differentiation (CD) markers (CD105+, CD73+, CD90+, CD45-, CD34-, CD14-, CD11b-, CD79a- or CD19- and HLA-DR-), their plastic adherence capacity and their multipotent differentiation potential when cultured in standard conditions as minimal quality [39]. However, it has been reported that positive markers of the ISCT panel are homogenously expressed among all MSC progeny [32]. Consistent with the literature, our protein analysis demonstrated that CD105, CD73, and CD90 were detectable but did not show a differential expression between MSCs, adipogenic and osteoblastic cells (Table 2). Additionally, all ISCT-defined markers that should present a very low protein abundance in MSCs have not been identified at all. These findings suggest that (a) our applied mass spectrometric workflow is capable of validating ISCT + -markers and (b) new protein markers to differentiate between MSCs, adipocytes, and osteoblasts are needed.

The model of the MSC differentiation into AD and $\mathrm{OB}$ allows us to determine their global proteome using quantitative mass spectrometry combined with neuronal networks and machine-learning algorithms for the first time. Interestingly, Aasebø et al. performed the only recent similar study and reported a strong separation of osteoblasts and MSCs [50] by comparing mass spectrometric data after data-dependent acquisition. However, and in contrast to our data, the proteome of adipocytes was not evaluated and only proteins were reported that showed an abundance level in the osteoblasts and not in the MSCs $(n=156)$. The findings of the here presented data considered positive and negative effect sizes $\left(\log _{2}\right.$ FC $\left.>|2|\right)$ resulting in 50 differentially expressed proteins between MSCs and osteoblasts. In line with the results presented by Aasebø, we detected decorin (DCN) and biglycan (BGN) as potential protein markers for osteoblastic differentiation (Supplementary Table S2): while BGN acts on the cell surface and is involved in the matrix mineralization [52-54], DCN was described to promote osteoblast differentiation fate [55]. It must be noted though that DCN could not be validated by machine learning algorithms and was thus not included in our final differentiation marker panel for osteoblastic differentiation.

\subsection{Osteoblastic Panel}

Overall, the applied algorithms revealed nine specific proteins for the osteoblastic differentiation, respectively. Analogous to BGN, cytochrome P450 family 24 subfamily A member 1 (CYP24A1), AE binding protein 1 (AEBP1), and collagen type III alpha 1 chain (COL3A1) concern functions of bone mineralization, osteoblastogenesis as well as matrix remodeling and thus confirmed a close association to the osteoblastic molecular differentiation module [56-60]. Strikingly, CYP24A1 presented the highest fold-change comparing $\mathrm{OB}$ to MSC ( $\left.\log _{2} \mathrm{FC} 3.65\right)$ and $\mathrm{OB}$ to $\mathrm{AD}\left(\log _{2} \mathrm{FC} 3.52\right)$. Further, three identified proteins were reported to be associated with osteoblastic diseases: while Stathmin 1 (STMN1) was 
described for osteoblast and osteoclast function [61] as well as for osteopenic phenotypes in mice [62], we found minichromosome maintenance complex component 4 (MCM4) which seems to play an important role during cell division and metastasis-free survival of osteosarcoma patients [63]. Further, prolyl 4-hydroxylase subunit alpha 1 (P4HA1) has been found as the active catalytic component of the prolyl 4-hydroxylase which catalyzes the post-translational formation of 4-hydroxyproline [64,65]. High P4HA1 gene and protein expression values have been recently described as a prognostic predictor in head and neck squamous cell carcinoma [66] as well as primary melanomas [67]. Additionally, P4HA1 is associated with the collagen-dependent bone disease osteogenesis imperfecta [68,69]: as P4HA1 is involved in the post-translational modification of collagens, a direct involvement in the pathogenesis of osteogenesis imperfecta is conceivable. Noteworthy, AEBP1 and MCM4 presented low protein levels in the AD and MSC groups making AEBP1+ and MCM4+ most suited as new OB or ISCT differentiation markers with a known osteoblastic background.

No literature link for osteoblastic differentiation or diseases was found for the proteins capping protein regulator and myosin 1 linker 1 (CARMIL1), and mesoderm specific transcript (MEST). While the CARMIL1 was more highly expressed in the OB than in the MSC and $\mathrm{AD}$ groups, the expression pattern for MEST was reduced. The plasma-membraneassociated protein CARMIL1 plays a role in the regulation of actin polymerization and cell migration. Specifically, CARMIL1 prevents the F-actin heterodimeric capping protein (CP) activity of migrating cells and thus stimulates actin polymerization [64]. In this context, it has been shown that activation of actin polymerization decreases osteoblast differentiation and bone formation in MSCs [70]. Since we observed high CARMIL1 levels in OBs, one could assume that the endpoint of an osteoblastic differentiation process is marked by high protein levels of CARMIL1 to activate actin polymerization and thus to stop cellular differentiation mechanisms.

Last, MEST—one of the markers with a low expression in osteoblastic cells-has been described to be involved in the mesoderm development and the regulation of lipid storage. Inline, it was described as a specific protein for the endoplasmic reticulum that co-localizes within lipid droplets in cells undergoing adipogenic differentiation [71]. Additionally, elevated gene expression of MEST in preadipocytes differentiating in adipocytes was described by Kadota et al. [72].

\subsection{Adipocytic Panel}

The differentiation of MSCs into adipocytes resulted in a higher expression of 13 proteins from which 10 support the work of other studies in this area. While fatty acid-binding protein 4 (FABP4), perilipin 1 and 4 (PLIN1/4), haptoglobin (HP), and CD36 have been described to be associated with adipogenesis, hydroxysteroid 11-beta dehydrogenase 1 (HSD11B1), monoamine oxidase A (MAOA), stearoyl-CoA desaturase (SCD), and adipose acyl-CoA synthetase-1 (ACSL1) demonstrate molecular function in adipose tissues [73-80]. FABP4 presented the highest differential expression compared to $\mathrm{OB}\left(\log _{2} \mathrm{FC} 7.04\right)$ and MSC $\left(\log _{2} \mathrm{FC} 6.77\right)$ and nearly no protein expression in the OD and MSC group. Associated with adipocytic processes, this finding could be used to implement FABP4+ as new $\mathrm{AB}$ or ISCT differentiation markers.

Noteworthy and to our best knowledge, no specific association to adipocyte differentiation was described for inter-alpha-trypsin inhibitor heavy chain 1 (ITIH1), RAP2A member of RAS oncogene family (RAP2A), epoxide hydrolase 1 (EPHX1), and phospholipid phosphatase 1 (PLPP1). While ITIH1 belongs to a protein family of related plasma serine protease inhibitors which is involved in extracellular matrix stabilization and the prevention of tumor metastasis [81], RAP2A is a small GTP binding protein that may regulate cytoskeletal rearrangements, cell migration, cell adhesion, and spreading [82]. EPHX1 is a member of the epoxide hydrolase family which plays a role in the metabolism of endogenous lipids such as epoxide-containing fatty acids [83] and fulfills a key function in the detoxification of xenobiotics [84]. Lastly, PLPP1 is a magnesium-independent phospholipid 
phosphatase of the plasma membrane and is associated with the regulation of inflammation, platelet activation, cell proliferation, and migration [85,86]. Against this background, it could be hypothesized that all four proteins may play a reasonable role in adipocytic processes. However, further studies including larger patient collectives are required.

In conclusion, this study set out to characterize undifferentiated MSCs and cells after osteoblastic and adipocytic differentiation on the proteome level. These experiments identified 22 highly cell type-specific proteins for MSCs, adipocytes, and osteoblasts using the combination of deep neural network-based quantification of data-independent mass spectrometry data. Overexpression of AEBP1 and MCM4 for OB as well as of FABP4 for AD differentiation seem to be the most promising molecular targets which could be used for regenerative medicine, stem cell, and cancer research in the future. Further studies to evaluate the molecular basis for bone formation including single-cell criteria and clinical patient data are warranted.

\section{Materials and Methods}

\subsection{Donors and Materials}

Bone marrow was aspirated from the lower extremities of five adult donors undergoing surgeries at the Department of Orthopedics and Traumatology, Odense University Hospital. The donor collective consisted of one male and four females. The bone marrow samples were considered as 'waste material' from routine operations and were thus collected without any extra patient risk. All donors received oral and written information and signed a consent. The project was approved by the Scientific Ethics Committee of Southern Denmark (project ID: S-20160084).

\subsection{Cell Isolation and Culture}

Bone marrow (5-10 mL) was collected into ethylenediaminetetraacetic acid (EDTA)coated vacutainers. MSCs were isolated from the mononuclear cell population following gradient centrifugation using Lymphoprep of the bone marrow, through plastic adherence, as described previously by Stenderup et al. [87]. The cells were cultured in minimum essential medium (MEM medium) supplemented with $10 \%$ fetal bovine serum (FBS) and 1\% penicillin/streptomycin $(\mathrm{P} / \mathrm{S})$ at $37{ }^{\circ} \mathrm{C}$ in a humidified incubator with $5 \% \mathrm{CO}_{2}$. The medium was switched to MEM medium supplemented with 10\% FBS, 1\% P/S, 1\% GlutaMAX, 1\% sodium pyruvate, and 1\% nonessential amino acids (S-MEM growing medium) after the first visualization of adherent cells. At $80 \%$ confluence, the cells were trypsinized and used for analysis and further cell expansion.

\subsection{Colony-Forming Unit-Fibroblast (CFU-f) Assay}

The colony-forming unit-fibroblast (CFU-f) assay was performed to assess the colonyforming capacity of cultured MSCs. The freshly isolated cells were counted in triplicates using a hemocytometer under an optical microscope and plated at a density of 1 million cells (passage 0) into three $22.1 \mathrm{~cm}^{2}$ Petri dishes (TPP, 93060). Standard culture conditions were used for 17 days and colonies were visualized by crystal violet staining.

\subsection{Cell Proliferation}

The cell proliferation capacity assay was performed at the first cell passage in triplicates. The cells were counted in a hemocytometer under an optical microscope, seeded (1000 cells/well) in a 6-well plate (TPP, 92006), and cultured under standard conditions. On days $1,3,6,9,12$, and 15, the cells were trypsinized and counted in a hemocytometer. The proliferation capacity of the cells was measured as the area under the curve (AUC).

\subsection{In Vitro Cell Differentiation}

\subsubsection{Osteoblastic Differentiation}

For the osteogenic differentiation, MSCs at first passage were seeded in a 4-well plate at a density of 20,000 cells $/ \mathrm{cm}^{2}$. At $90 \%$ confluence (after $24 \mathrm{~h}$ ), cell culture media 
were replaced with osteoblastic induction media containing: 10\% FBS, 1\% P/S, $5 \mathrm{mM}$ $\beta$-glycerophosphate, $10 \mathrm{nM}$ dexamethasone, $50 \mu \mathrm{g} / \mathrm{mL}$ vitamin $\mathrm{C}$, and $10 \mathrm{nM}$ vitamin $\mathrm{D}_{3}$. Osteoblastic induction media were replaced every 2-3 days. After 14 days, the osteoblastic differentiation was assessed by visualization of mineralized matrix formation via alizarin red staining. The cells were washed with PBS and fixed with $70 \%$ ice-cold ethanol at $-20{ }^{\circ} \mathrm{C}$ for $1 \mathrm{~h}$. Afterwards, the cells were washed with Milli-Q and incubated with alizarin red $(\mathrm{pH}=4.2)$ for $10 \mathrm{~min}$ with rotation at room temperature (RT). Subsequently, the staining intensity of alizarin red was quantified using ImageJ software.

\section{Alkaline Phosphatase (ALP) Activity}

The alkaline phosphatase (ALP) activity is a common biochemical measure for osteoblast activity. Cells were washed with tris-buffered saline $(\mathrm{pH} 9)$, fixed with $3.7 \%$ formaldehyde-90\% ethanol for $30 \mathrm{~s}$ at RT, and incubated with p-nitrophenyl phosphate $(1 \mathrm{mg} / \mathrm{mL})$ in $50 \mathrm{mM} \mathrm{NaHCO}_{3}$ and $1 \mathrm{mM} \mathrm{MgCl}_{2}, \mathrm{pH} 9.6$ at $37^{\circ} \mathrm{C}$. After $20 \mathrm{~min}$ of incubation, $3 \mathrm{M} \mathrm{NaOH}$ was added to stop the reaction. Absorbance was measured at $405 \mathrm{~nm}$, and ALP activity values were corrected for the number of cells in each well. The cell number was determined as a measure of cell viability and determined by incubating the cells with CellTiter-Blue for $1 \mathrm{~h}$ at $37^{\circ} \mathrm{C}$. The fluorescent intensity at 560/590 $\mathrm{nm}$ (excitation/emission) was measured in the FLUOstar Omega plate reader.

\subsubsection{Adipocytic Differentiation}

MSCs of the first passage were plated at a density of 30,000 cells $/ \mathrm{cm}^{2}$ in a 4-well plate for $24 \mathrm{~h}$. At near full confluence, the media were replaced with adipocytic induction media containing Dulbecco's modified Eagle's medium (DMEM) supplemented with 10\% FBS, 1\% P/S, 5\% horse serum, $1 \mu \mathrm{M}$ rosiglitazone (BRL) 49,653, $3 \mu \mathrm{g} / \mathrm{mL}$ insulin, $100 \mathrm{nM}$ dexamethasone and $225 \mu \mathrm{M}$ 3-isobutyl-1-methylxanthine (IBMX). Media were changed every 2-3 days. After 14 days, adipocytic differentiation efficiency was determined by visualizing the formation of mature adipocytes containing lipid droplets using Oil Red O staining. The cells were fixed with $4 \%$ paraformaldehyde (PFA) for $10 \mathrm{~min}$ at RT, washed with $3 \%$ isopropanol, and incubated with filtered Oil Red O solution ( $25 \mathrm{mg}$ of Oil Red O in $5 \mathrm{~mL}$ of $100 \%$ isopropanol and $3.35 \mathrm{~mL}$ Milli-Q). Photomicrographs of the differentiated cells were captured using an Olympus optical microscope ( $\times 10$ magnification objective) and quantified as the area of lipid droplets (average of 6 images per sample) using ImageJ software.

\subsection{Flow Cytometry}

Flow cytometry was used for measuring the expression of surface CD markers for MSC characterization. After ex vivo expansion to passage 2, MSCs were trypsinized and washed with phosphate-buffered saline (PBS) (without $\mathrm{Ca}^{2+}$ and $\mathrm{Mg}^{2+}$ ) containing $2 \%$ FBS. The cells were incubated with primary fluorophore-conjugated antibodies as follows: CD14-PE, CD44-PE, CD34-PE, CD73-PE, CD90-PE, CD105-PE and ALPL-APC for 25 min at $4{ }^{\circ} \mathrm{C}$. After the incubation, MSCs were washed twice to remove antibodies with unspecific binding and were analyzed using a BD LSR II Flow Cytometer and the BD FACSDiva software. The data were analyzed with Kaluza Flow Cytometry Analysis Software Version 1.3 (Beckman Coulter, Brea, CA, USA).

\subsection{Cell Isolation for Mass Spectrometry Analysis}

Five samples per cell lineage derived from bone marrow donors (patient numbers $11,13,15,17$, and 18) were selected and prepared for mass spectrometry analysis: (a) MSCs without differentiation; (b) MSCs after osteoblastic differentiation (osteoblasts); (c) MSCs after adipocytic differentiation (adipocytes). The Protease-Inhibitor (PIH) buffer was prepared as follows: $4 \mu \mathrm{L}$ aprotinin $(1: 1000)+4 \mu \mathrm{L}$ leupeptin $(1: 1000)+80 \mu \mathrm{L}$ phenylmethylsulfonyl fluoride (PMSF) (1:50) in 3.91 mL 2-D Lysis Buffer. The cells were washed twice with $10 \mathrm{~mL}$ DPBS at $4{ }^{\circ} \mathrm{C}$. Afterwards, the cells were scraped off the plate into $1.7 \mathrm{~mL}$ 
ice-cold PIH buffer centrifuged at $660 \times g$ for 3 min at $4{ }^{\circ} \mathrm{C}$. The pellet was resuspended in $1 \mathrm{~mL}$ PIH buffer and transferred to pre-weighted cryo-tubes and centrifuged at $2700 \times g$ for $5 \mathrm{~min}$ at $4{ }^{\circ} \mathrm{C}$. The pellet was frozen at $-80^{\circ} \mathrm{C}$.

\subsection{Two-Dimensional Fluorescence Gel Electrophoresis}

The samples were assessed as described previously [88]. Briefly, samples were lyophilized and subsequently dissolved in a DIGE lysis buffer (30 mM Tris, 7M Urea, 2M Thiourea, 4\% CHAPS (3-[(3-Cholamidopropyl)-dimethylammonio]-1-propansulfonat Hydrate)). Subsequently, protein samples were precipitated with the trichloroacetic acid (TCA)-like ReadyPrep 2-D Cleanup Kit (Bio-Rad Laboratories, Hercules, CA, USA) as specified by the manufacturer. Total protein concentration was determined in quadruples using the fluorescence-based EZQ Protein Quantitation Kit (Life Technologies, Carlsbad, CA, USA) according to the manufacturer's protocol.

After labeling the protein samples with the fluorescence-based Refraction-2D Labelling Kit (NH DyeAGNOSTIC, Germany), proteins were diluted with rehydration sample buffer (7 M urea, $2 \mathrm{M}$ thiourea, 2\% (w/v) CHAPS, 2\% (v/v) carrier ampholytes ( $\mathrm{pH} 4-7)$ and bromophenol blue) and applied to immobilized $\mathrm{pH}$ gradient (IPG) gel strips, with a $\mathrm{pH}$ range 4-7 (Immobiline DryStrip pH 4-7, 24 cm, linear, GE Healthcare, Chicago, IL, USA). Isoelectric focusing (IEF) was carried out in a Protean 12 IEF cell (Bio-Rad Laboratories, USA) at $20^{\circ} \mathrm{C}$ reaching approximately $57,700 \mathrm{Vh}$. The horizontal second dimension (HPE FlatTop Tower, SERVA Electrophoresis, Heidelberg, Germany) was carried out by sodium dodecyl sulfate-polyacrylamide gel electrophoresis (SDS-PAGE) on 12.5\% acrylamide gels (2DHPE Large Gel NF 12.5\% Kit, $0.65 \times 200 \times 255$ mm, SERVA Electrophoresis, Heidelberg, Germany). Electrophoresis was performed with $1500 \mathrm{~V}$ for $4 \mathrm{~h} 50$ min reaching approximately $3400 \mathrm{Vh}$.

Gel image acquisition was performed using the Typhoon FLA 9000 laser scanner (GE Healthcare, UK). Subsequently, protein spots were evaluated using the software Progenesis SameSpots (Nonlinear Dynamics, Newcastle upon Tyne, UK, v4.1). The analysis included protein spot detection, background subtraction, and relative quantification.

\subsection{Sample Preparation for High-Performance Liquid Chromatography (HPLC) and Electrospray Ionization Tandem Mass Spectrometry (ESI-MS/MS)}

The sample preparation for mass spectrometry analysis was performed with a filter aided sample preparation (FASP) protocol [89]. Briefly, $100 \mu \mathrm{g}$ samples diluted in $200 \mu \mathrm{L}$ $8 \mathrm{M}$ uric acid in 0.1 M Tris-HCL (UA) were added to filter columns (30 k, AmiconUltra, Merck, Darmstadt, Germany) and centrifuged at RT, 14,000× $g$ for $15 \mathrm{~min}$. Additional $200 \mu \mathrm{L}$ UA was added to the filter column and repeatedly centrifuged. After discarding the eluate, $100 \mu \mathrm{L} 0.05 \mathrm{M}$ IAA (solubilized in UA) was added to the filter column and incubated in the dark at RT for $20 \mathrm{~min}$. The column was washed two times with UA before $100 \mu \mathrm{L}$ $0.05 \mathrm{M}$ ammonium bicarbonate $(\mathrm{ABC})$ buffer was added to the columns and centrifugation at RT, $14,000 \times g$ for $10 \mathrm{~min}$, twice. Next, $40 \mu \mathrm{L}$ trypsin in ABC (enzyme:protein ratio 1:100) was added and left for incubation in a humid chamber at $37{ }^{\circ} \mathrm{C}$ overnight. The columns were centrifuged at RT $(14,000 \times g$ for $10 \mathrm{~min})$ before $40 \mu \mathrm{L}$ of ABC were added. Finally, the filtrate was collected, lyophilized, and stored at $-20^{\circ} \mathrm{C}$ after centrifugation at $14,000 \times g$ for $10 \mathrm{~min}$.

\subsection{High-Performance Liquid Chromatography (HPLC) and Electrospray Ionization Tandem Mass Spectrometry (ESI-MS/MS)}

The samples were solubilized with a final concentration of $1 \mu \mathrm{g} / \mu \mathrm{L}$ in solvent $\mathrm{A}$ (0.1\% formic acid) and were loaded into a HPLC Dionex Ultimate 3000 (Thermo Fisher Scientific, Waltham, MA, USA). The samples were first loaded onto a trap column $(\mu-$ Precolumn Acclaim PepMap100, internal diameter: $0.3 \times 5 \mathrm{~mm}, 5 \mu \mathrm{m}, 100 \AA$, Thermo Fisher Scientific, Waltham, MA, USA) and desalted with loading solution at $10 \mu \mathrm{L} / \mathrm{min}$ for $4 \mathrm{~min}$. Peptides were subsequently separated using an analytical column (LC Column, $3 \mu \mathrm{m} \mathrm{C18} \mathrm{(2),} 0.3 \times 50$ mm, $3 \mu \mathrm{m}, 100 \AA$ A, Phenomenex Inc., Torrence, CA, USA) and eluted 
with a multi-step gradient of solvent B ( $0.1 \%$ formic acid in acetonitrile) in solvent $A$ for $86 \mathrm{~min}$ at a flow rate of $5 \mu \mathrm{L} / \mathrm{min}$. Purified peptides were analyzed with a TripleTOF 5600+ mass spectrometer (AB ScieX, Framingham, MA, USA). The following SWATH (sequential window acquisition of all theoretical mass spectra) acquisition working parameters were used: Ion Spray Voltage Floating (ISVF) at 5000 V; ion source gas (GS1), 15; ion source gas (GS2), 0; curtain gas (CUR) at 30 and source temperature heating set to $0{ }^{\circ} \mathrm{C}$. The optimized declustering potential (DP) was set at 100; collision energy (CE) to 19.2; collision energy spread (CES), 5.0; ion release delay (IRD), 67; ion release width (IRW) at 25. For data acquisition, one 0.049965 s MS scan (m/z 350-1250) was performed, followed by 100 variable Q1 windows with the size range 5-91.3 Da, each at $0.030 \mathrm{~s}$ accumulation time with CES at $5 \mathrm{eV}$. The precursor isolation windows were defined using the SWATH Variable Window Calculator V1.1 (AB Sciex) based on precursor $m / z$ densities obtained from DDA spectra. For DDA acquisition, identical instrument working parameters were used. MS scans were performed for 350-1250 Da with an accumulation time of $0.25 \mathrm{~s}$, MS/MS scans were performed for 100-1500 Da with an accumulation time of $0.05 \mathrm{~s}$ at high sensitivity mode.

\subsection{SWATH Data Processing}

The raw SWATH data were processed using the software tool DIA-NN v1.7.16 (dataindependent acquisition by neural networks) developed by Vadim Demichev et al. [90]. The software was used in the high accuracy LC mode with RT-dependent cross-normalization enabled. Mass accuracy, MS1 accuracy, and scan window settings were set to 0, as DIA-NN optimizes these parameters automatically. The 'match between runs' function was used to first develop a spectral library using the 'smart profiling strategy' from the data-independent acquisition data. The human UniProtKB/swiss-prot database (version 2020/12/6) [91] was used for protein inference from identified peptides. Trypsin/P was specified as protease. The precursor ion generation settings were set to peptide length of 7-52 amino acids, the maximum number of missed cleavages to one. The maximum number of variable modifications was set to zero. N-terminal methionine excision and cysteine carbamidomethylation were enabled as fixed modifications. The neural network classifier was set to double-pass mode as it typically generates the best results and analysis time was not an issue here. The resulting report file was further processed in the DIA-NN $\mathrm{R}$ package [90] for MaxLFQ-based [92] protein quantification. A report was generated containing unique proteins (proteins that were not assigned to a group of homologs) that passed the FDR cut-off of 0.01 applied on the precursor level and were identified and quantified using proteotypic peptides only. All proteins in the final dataset were identified by at least two unique peptides. The proteins were mapped for their corresponding gene names, which were required for downstream analysis steps such as gene enrichment analysis. In this context, the terms proteins and genes are used interchangeably in this study report.

The mass spectrometry proteomics data have been deposited to the ProteomeXchange Consortium [93] via the PRIDE [94] partner repository with the dataset identifier PXD029900.

\subsection{Quantitative Data Processing}

The dataset was further processed with the R [95] package DEP [96], which allows for missing value filtering and imputation: proteins/genes that were not reliably identified in 4 out of 5 replicates of at least one condition were removed from the dataset. Variance stabilizing normalization was applied to the remaining dataset using the $\mathrm{R}$ package vsn [97]. To analyze all identified proteins, remaining missing values were imputed with a multiple imputation strategy, as those can conserve differential expression, maintain the original informational content of the dataset, and respect low concentrated/not detectable proteins $[96,98]$. Missing values were considered as missing not at random (MNAR) when protein quantity data were completely missing for at least one condition. All other missing values were considered missing at random (MAR). While MNAR were imputed with 
random draws from a Gaussian distribution centered around a minimal value, MAR were imputed with a k-nearest neighbor model. The imputed dataset was used for subsequent statistical analysis.

\subsection{Data Analysis}

The gene name of the corresponding protein was used for analyses. The bioinformatics platform Omics Playground v2.7.18 (BigOmics Analytics, Lugano, Switzerland) was partly used for protein quantity data analysis and visualization [99]. For a clustering analysis and visualization of the high-dimensional quantitative proteomics data, a principal components analysis plot was computed using the stats package provided by the R software suite [95], and visualized with the R package ggplot2 [100]. A heatmap (two-way hierarchical clustering) was computed in Omics Playground. Using the R package NbClust [101], we utilized several algorithms for the estimation of the adequate cluster numbers within the data set of the top 50 differentially expressed proteins (selected via their standard deviation). According to a majority vote of the NbClust algorithms, three is the best number of clusters for this data set. Thus, 'three clusters' was used as a parameter for the initialization of the unsupervised two-way hierarchical clustering method included in the Omics Playground software suite. The method was applied to the data set of the top 50 proteins and used to generate the heatmap.

The gene set enrichment was computed with Omics Playground using the merged results of the Fisher's exact test [102], fGSEA [103], and GSVA [104], thereby applying a FDR $<0.05$ (which corresponds to a so-called 'meta.q value' which corresponds to the highest q-value provided by the used statistical methods) and absolute $\left|\log _{2} \mathrm{FC}\right|$ threshold of $>0.2$. The MSigDB gene set collection was used as the target database for the enrichment. All measured genes are used as 'universe' after filtering for non-expressed genes. The $\log _{2} \mathrm{FC}$ is calculated as the average $\log _{2} \mathrm{FC}$ of all genes identified in the particular gene set.

For a differential protein expression analysis, a Welch-ANOVA was computed using the stats package. The results of the Welch-ANOVA were corrected for multiple testing via the Benjamini-Hochberg procedure [105], selecting the candidates for post-hoc testing with a FDR of $<0.05$. Post-hoc testing was performed via the Tukey honestly significant difference (HSD) method using the TukeyHSD function of the R software suite. Significant differential protein expression was considered at a $q$-value of $<0.05$ and an absolute logarithmic fold change $\left(\mid \log _{2} \mathrm{FCl}\right)$ of $>2$. Volcano plots were created from the results of the differential expression analysis, using the plot function in R. For better visualization, the $\log _{10} \mathrm{q}$-values of the ANOVA were plotted on the $y$-axis and $\log _{2}$ FC on the $x$-axis. A Venn diagram was created using the web tool InteractiVenn [106], using the differentially expressed proteins of the three comparisons as input sets. Boxplots for overlapping proteins were created in the R software suite using ggplot2. The 'biomarker' module of Omics Playground was used for the ranking of biomarkers that could be suitable for the characterization of the cell lineage. Here, a cumulative variable importance score for each feature was calculated using machine learning algorithms, including LASSO [41], elastic nets [42], random forests [43], and extreme gradient boosting [44] and provides the top 40 features according to the ranking of the cumulative score by the algorithms. The findings of the machine learning algorithms were used as further validation of our marker panels derived from classical statistical testing. The Panther classification system was used for the annotation of all overlapping proteins according to gene ontology terms of the biological process, molecular function, and cellular component [107].

\subsection{Reagents}

Lymphoprep (StemCell Technologies, Vancouver, Canada, 1114545), minimum essential media (MEM, Gibco/Thermo Fisher Scientific, Waltham, MA, USA, 31095-029), Dulbecco's modified Eagle's medium (DMEM, Gibco/Thermo Fisher Scientific, 31966), fetal bovine serum (Thermo Fisher Scientific, Waltham, MA, USA, 10270106), GlutaMAX (Gibco/Thermo Fisher Scientific, 35050-038), non-essential amino acids (MEM NEAA, 
Gibco/Thermo Fisher Scientific, 11140-035), Trypsin-EDTA (Invitrogen/Thermo Fisher Scientific, 25300062), $\beta$-glycerophosphate (Calbiochem/Merck, Darmstadt, Germany, 35675), dexamethasone (Sigma/Merck, Darmstadt, Germany, D4902), vitamin C (L-Ascorbic Acid Phosphate Magnesium Salt n-Hydrate, Wako, Neuss, Germany, 013-12061), vitamin D3 $(1 \alpha, 25$-Dihydroxyvitamin D3 a kind gift from Leo Pharma, Ballerup Sogn, Denmark), pnitrophenyl phosphate (Sigma/Merck, 71768), Alizarin Red (Sigma/Merck, A5533), Oil Red O (Sigma/Merck, O0625), horse serum (Sigma/Merck, H1270), rosiglitazone (BRL, Cayman Chemical, Ann Arbor, MI, USA, 71740), insulin (Sigma/Merck, I9278), 3-isobutyl1-methylxanthine (IBMX, Sigma/Merck, I5879), Napthol AS-TR phosphate disodium salt (Sigma/Merck, N6125), Fast Red TR Salt hemi (zinc chloride) salt (Sigma/Merck, F8764), anti-CD14 (BD Pharmingen, Franklin Lakes, NJ, USA, 555398), anti-CD44 (Beckman Coulter, Brea, CA, USA A32537), anti-CD34 (BD Biosciences, Franklin Lakes, NJ, USA, 555822), anti-CD73 (BD Bioscience, 550257), anti-CD90 (Beckman Coulter, IM3600U), anti-CD105 (Beckman Coulter, A07414), anti-ALPL (R\&D Systems, Minneapolis, MN, USA, FAB1448A), CellTiter-Blue cells viability assay reagent (Promega, Walldorf, Germany, G8081), TRIzol (Invitrogen/Thermo Fisher Scientific, 15596018), High-Capacity cDNA Reverse Transcription Kit (Applied Biosystems, 4368813), Fast SYBR Green Master Mix (Applied Biosystems/Thermo Fisher Scientific, Waltham, MA, USA 4385614), RNAse (Affymetrix, Santa Clara, CA, USA, 78020Y), DNAse (Worthington, Columbus, OH, USA, DPRF), Tris (Merck, 1083821000), uric acid (Affymetrix, 75826), thiourea (Sigma/Merck, 33717), CHAPS (Sigma/Merck, C5070-1G), ReadyPrep 2-D Cleanup Kit (Bio-Rad Laboratories, Hercules, CA, USA, 163-21-30), Tris-HCL (Roth, Karlruhe, Germany, 48551), ammoniumbicarbonate (Honeywell, Morristown, NJ, USA, 1066-33-7), iodacetamide (Sigma/Merck, 163-2109), Trypsin gold (Promega, V5280), formic acid (Baker, 9820), acetonitrile (Baker/Thermo Fisher Scientific, 9017).

Supplementary Materials: The following supporting information can be downloaded at: https: //www.mdpi.com/article/10.3390/ijms23052568/s1.

Author Contributions: Conceptualization, J.M.K., M.K. (Moustapha Kassem), J.K.H. and T.G.; data curation, T.S., G.F., M.K. (Michael Kohl), J.M.K. and T.G.; formal analysis, T.S., G.F., M.K. (Michael Kohl), J.M.K. and T.G.; funding acquisition, J.M.K., A.-P.S., M.K. (Moustapha Kassem), J.K.H. and T.G.; methodology, T.S., G.F., M.K. (Michael Kohl), S.R., J.H., I.K., S.H. and T.G.; resources, J.M.K., H.S. and T.G.; software, I.K.; supervision T.G.; visualization, T.S. and M.K. (Michael Kohl); writing-original draft, T.S., G.F., M.K. (Michael Kohl) and T.G.; writing-review and editing, J.M.K., S.R., J.H., H.S., I.K., A.-P.S., S.H., M.K. (Moustapha Kassem) and J.K.H. All authors have read and agreed to the published version of the manuscript.

Funding: The study was performed as a part of the BONEBANK project (project number: 16-1.0-15) supported by Interreg 5a Germany-Denmark with funds from the European Regional Development.

Institutional Review Board Statement: The project was approved by the Scientific Ethics Committee of Southern Denmark (project ID: S-20160084).

Informed Consent Statement: All donors received oral and written information and signed a consent.

Data Availability Statement: The mass spectrometry proteomics data have been deposited to the ProteomeXchange Consortium [93] via the PRIDE [94] partner repository with the dataset identifier PXD029900.

Acknowledgments: This work was supported by the German Network for Bioinformatics Infrastructurede.NBI, service center BioInfra.Prot, funded by the German Federal Ministry of Education and Research (BMBF) - Grant FKZ 031 A 534A. Additionally, we would like to thank V. Demichev for the support with the DIA-NN software. T. Sauer is grateful for the support from the Ad Infinitum Foundation.

Conflicts of Interest: All authors declare that they have no competing financial interest. IK is CTO of BigOmics Analytics SA, the creator of the Omics Playground. TG is a member of the BigOmics Analytics Advisory Board. 


\section{References}

1. Friedenstein, A.Y. Induction of bone tissue by transitional epithelium. Clin. Orthop. Relat. Res. 1968, 59, 21-37. [CrossRef] [PubMed]

2. Ullah, M.; Liu, D.D.; Thakor, A.S. Mesenchymal Stromal Cell Homing: Mechanisms and Strategies for Improvement. iScience 2019, 15, 421-438. [CrossRef] [PubMed]

3. Singer, N.G.; Caplan, A.I. Mesenchymal stem cells: Mechanisms of inflammation. Annu. Rev. Pathol. 2011, 6, 457-478. [CrossRef]

4. Le Blanc, K.; Mougiakakos, D. Multipotent mesenchymal stromal cells and the innate immune system. Nat. Rev. Immunol. 2012, 12, 383-396. [CrossRef]

5. $\quad$ Bronckaers, A.; Hilkens, P.; Martens, W.; Gervois, P.; Ratajczak, J.; Struys, T.; Lambrichts, I. Mesenchymal stem/stromal cells as a pharmacological and therapeutic approach to accelerate angiogenesis. Pharmacol. Ther. 2014, 143, 181-196. [CrossRef]

6. Yun, C.W.; Lee, S.H. Enhancement of Functionality and Therapeutic Efficacy of Cell-Based Therapy Using Mesenchymal Stem Cells for Cardiovascular Disease. Int. J. Mol. Sci. 2019, 20, 982. [CrossRef] [PubMed]

7. Kim, J.; Shapiro, L.; Flynn, A. The clinical application of mesenchymal stem cells and cardiac stem cells as a therapy for cardiovascular disease. Pharmacol. Ther. 2015, 151, 8-15. [CrossRef]

8. $\quad$ Chung, M.-J.; Son, J.-Y.; Park, S.; Park, S.-S.; Hur, K.; Lee, S.-H.; Lee, E.-J.; Park, J.-K.; Hong, I.-H.; Kim, T.-H.; et al. Mesenchymal Stem Cell and MicroRNA Therapy of Musculoskeletal Diseases. Int. J. Stem. Cells 2021, 14, 150-167. [CrossRef]

9. Kim, M.; Kim, K.H.; Song, S.U.; Yi, T.G.; Yoon, S.H.; Park, S.R.; Choi, B.H. Transplantation of human bone marrow-derived clonal mesenchymal stem cells reduces fibrotic scar formation in a rat spinal cord injury model. J. Tissue Eng. Regen. Med. 2018, 12, e1034-e1045. [CrossRef]

10. Wei, X.; Yang, X.; Han, Z.P.; Qu, F.F.; Shao, L.; Shi, Y.F. Mesenchymal stem cells: A new trend for cell therapy. Acta Pharm. Sin. 2013, 34, 747-754. [CrossRef]

11. Yong, K.W.; Choi, J.R.; Wan Safwani, W.K. Biobanking of Human Mesenchymal Stem Cells: Future Strategy to Facilitate Clinical Applications. Adv. Exp. Med. Biol. 2016, 951, 99-110. [CrossRef] [PubMed]

12. Lee, H.-Y.; Hong, I.-S. Double-edged sword of mesenchymal stem cells: Cancer-promoting versus therapeutic potential. Cancer Sci. 2017, 108, 1939-1946. [CrossRef]

13. Knight, M.N.; Hankenson, K.D. Mesenchymal Stem Cells in Bone Regeneration. Adv. Wound Care New Rochelle 2013, 2, 306-316. [CrossRef] [PubMed]

14. Marcacci, M.; Kon, E.; Moukhachev, V.; Lavroukov, A.; Kutepov, S.; Quarto, R.; Mastrogiacomo, M.; Cancedda, R. Stem cells associated with macroporous bioceramics for long bone repair: 6- to 7-year outcome of a pilot clinical study. Tissue Eng. 2007, 13, 947-955. [CrossRef] [PubMed]

15. Giannotti, S.; Trombi, L.; Bottai, V.; Ghilardi, M.; D'Alessandro, D.; Danti, S.; Dell'Osso, G.; Guido, G.; Petrini, M. Use ofautologous human mesenchymal stromal cell/fibrin clot constructs in upper limb non-unions: Long-term assessment. PLoS ONE 2013, 8, e73893. [CrossRef]

16. Quarto, R.; Mastrogiacomo, M.; Cancedda, R.; Kutepov, S.M.; Mukhachev, V.; Lavroukov, A.; Kon, E.; Marcacci, M. Repair of large bone defects with the use of autologous bone marrow stromal cells. N. Engl. J. Med. 2001, 344, 385-386. [CrossRef]

17. Liebergall, M.; Schroeder, J.; Mosheiff, R.; Gazit, Z.; Yoram, Z.; Rasooly, L.; Daskal, A.; Khoury, A.; Weil, Y.; Beyth, S. Stem cell-based therapy for prevention of delayed fracture union: A randomized and prospective preliminary study. Mol. Ther. 2013, 21, 1631-1638. [CrossRef]

18. Oryan, A.; Kamali, A.; Moshiri, A.; Baghaban Eslaminejad, M. Role of Mesenchymal Stem Cells in Bone Regenerative Medicine: What Is the Evidence? Cells Tissues Organs 2017, 204, 59-83. [CrossRef]

19. Shi, L.; Huang, H.; Lu, X.; Yan, X.; Jiang, X.; Xu, R.; Wang, S.; Zhang, C.; Yuan, X.; Xu, Z.; et al. Effect of human umbilical cordderived mesenchymal stem cells on lung damage in severe COVID-19 patients: A randomized, double-blind, placebo-controlled phase 2 trial. Signal. Transduct Target. Ther. 2021, 6, 58. [CrossRef]

20. Ciuffreda, M.C.; Malpasso, G.; Musarò, P.; Turco, V.; Gnecchi, M. Protocols for in vitro Differentiation of Human Mesenchymal Stem Cells into Osteogenic, Chondrogenic and Adipogenic Lineages. Methods Mol. Biol. 2016, 1416, 149-158. [CrossRef]

21. O'Keefe, R.J.; Tuan, R.S.; Lane, N.E.; Awad, H.A.; Barry, F.; Bunnell, B.A.; Colnot, C.; Drake, M.T.; Drissi, H.; Dyment, N.A.; et al. American Society for Bone and Mineral Research-Orthopaedic Research Society Joint Task Force Report on Cell-Based Therapies. J. Bone Miner. Res. 2020, 35, 3-17. [CrossRef] [PubMed]

22. Gómez-Barrena, E.; Rosset, P.; Müller, I.; Giordano, R.; Bunu, C.; Layrolle, P.; Konttinen, Y.T.; Luyten, F.P. Bone regeneration: Stem cell therapies and clinical studies in orthopaedics and traumatology. J. Cell Mol. Med. 2011, 15, 1266-1286. [CrossRef]

23. Fakhry, M.; Hamade, E.; Badran, B.; Buchet, R.; Magne, D. Molecular mechanisms of mesenchymal stem cell differentiation towards osteoblasts. World J. Stem Cells 2013, 5, 136-148. [CrossRef] [PubMed]

24. Zaher, W.; Harkness, L.; Jafari, A.; Kassem, M. An update of human mesenchymal stem cell biology and their clinical uses. Arch. Toxicol. 2014, 88, 1069-1082. [CrossRef] [PubMed]

25. Centeno, C.J.; Al-Sayegh, H.; Freeman, M.D.; Smith, J.; Murrell, W.D.; Bubnov, R. A multi-center analysis of adverse events among two thousand, three hundred and seventy two adult patients undergoing adult autologous stem cell therapy for orthopaedic conditions. Int. Orthop. 2016, 40, 1755-1765. [CrossRef] [PubMed]

26. Pittenger, M.F.; Discher, D.E.; Péault, B.M.; Phinney, D.G.; Hare, J.M.; Caplan, A.I. Mesenchymal stem cell perspective: Cell biology to clinical progress. NPJ Regen. Med. 2019, 4, 22. [CrossRef] 
27. Bianco, P.; Robey, P.G.; Simmons, P.J. Mesenchymal stem cells: Revisiting history, concepts, and assays. Cell Stem Cell 2008, 2, 313-319. [CrossRef]

28. Post, S.; Abdallah, B.M.; Bentzon, J.F.; Kassem, M. Demonstration of the presence of independent pre-osteoblastic and preadipocytic cell populations in bone marrow-derived mesenchymal stem cells. Bone 2008, 43, 32-39. [CrossRef]

29. Larsen, K.H.; Frederiksen, C.M.; Burns, J.S.; Abdallah, B.M.; Kassem, M. Identifying a molecular phenotype for bone marrow stromal cells with in vivo bone-forming capacity. J. Bone Miner. Res. 2010, 25, 796-808. [CrossRef]

30. McLeod, C.M.; Mauck, R.L. On the origin and impact of mesenchymal stem cell heterogeneity: New insights and emerging tools for single cell analysis. Eur. Cell Mater. 2017, 34, 217-231. [CrossRef]

31. Elsafadi, M.; Manikandan, M.; Atteya, M.; Hashmi, J.A.; Iqbal, Z.; Aldahmash, A.; Alfayez, M.; Kassem, M.; Mahmood, A. Characterization of Cellular and Molecular Heterogeneity of Bone Marrow Stromal Cells. Stem Cells Int. 2016, $2016,9378081$. [CrossRef] [PubMed]

32. Kowal, J.M.; Schmal, H.; Halekoh, U.; Hjelmborg, J.B.; Kassem, M. Single-cell high-content imaging parameters predict functional phenotype of cultured human bone marrow stromal stem cells. Stem Cells Transl. Med. 2020, 9, 189-202. [CrossRef] [PubMed]

33. Keating, A. Mesenchymal stromal cells. Curr. Opin. Hematol. 2006, 13, 419-425. [CrossRef] [PubMed]

34. Hunt, C.J. Cryopreservation of Human Stem Cells for Clinical Application: A Review. Transfus. Med. Hemother. 2011, 38, 107-123. [CrossRef] [PubMed]

35. Shen, W.; Chen, J.; Gantz, M.; Punyanitya, M.; Heymsfield, S.B.; Gallagher, D.; Albu, J.; Engelson, E.; Kotler, D.; Pi-Sunyer, X.; et al. MRI-measured pelvic bone marrow adipose tissue is inversely related to DXA-measured bone mineral in younger and older adults. Eur. J. Clin. Nutr. 2012, 66, 983-988. [CrossRef]

36. Li, C.J.; Cheng, P.; Liang, M.K.; Chen, Y.S.; Lu, Q.; Wang, J.Y.; Xia, Z.Y.; Zhou, H.D.; Cao, X.; Xie, H.; et al. MicroRNA-188 regulates age-related switch between osteoblast and adipocyte differentiation. J. Clin. Investig. 2015, 125, 1509-1522. [CrossRef]

37. Liao, L.; Yang, X.; Su, X.; Hu, C.; Zhu, X.; Yang, N.; Chen, X.; Shi, S.; Shi, S.; Jin, Y. Redundant miR-3077-5p and miR-705 mediate the shift of mesenchymal stem cell lineage commitment to adipocyte in osteoporosis bone marrow. Cell Death Dis. 2013, 4, e600. [CrossRef]

38. Kowal, J.M.; Möller, S.; Ali, D.; Figeac, F.; Barington, T.; Schmal, H.; Kassem, M. Identification of a clinical signature predictive of differentiation fate of human bone marrow stromal cells. Stem Cell Res. 2021, 12, 265. [CrossRef]

39. Dominici, M.; Le Blanc, K.; Mueller, I.; Slaper-Cortenbach, I.; Marini, F.; Krause, D.; Deans, R.; Keating, A.; Prockop, D.; Horwitz, E. Minimal criteria for defining multipotent mesenchymal stromal cells. The International Society for Cellular Therapy position statement. Cytotherapy 2006, 8, 315-317. [CrossRef]

40. Liberzon, A.; Birger, C.; Thorvaldsdóttir, H.; Ghandi, M.; Mesirov, J.P.; Tamayo, P. The Molecular Signatures Database Hallmark Gene Set Collection. Cell Syst. 2015, 1, 417-425. [CrossRef]

41. Friedman, J.; Hastie, T.; Tibshirani, R. Regularization Paths for Generalized Linear Models via Coordinate Descent. J. Stat. Softw 2010, 33, 1-22. [CrossRef] [PubMed]

42. Zou, H.; Hastie, T. Regularization and variable selection via the elastic net. J. R. Stat. Soc. Ser. B Stat. Methodol. 2005, 67, 301-320. [CrossRef]

43. Breiman, L. Random Forests. Mach. Learn. 2001, 45, 5-32. [CrossRef]

44. Chen, T.; Guestrin, C. XGBoost: A Scalable Tree Boosting System. In Proceedings of the 22nd ACM SIGKDD International Conference on Knowledge Discovery and Data Mining, San Francisco, CA, USA, 13-17 August 2016; pp. 785-794.

45. Liao, Y.-J.; Tang, P.-C.; Chen, Y.-H.; Chu, F.-H.; Kang, T.-C.; Chen, L.-R.; Yang, J.-R. Porcine induced pluripotent stem cell-derived osteoblast-like cells prevent glucocorticoid-induced bone loss in Lanyu pigs. PLoS ONE 2018, 13, e0202155. [CrossRef]

46. Yamada, M.; Watanabe, J.; Ueno, T.; Ogawa, T.; Egusa, H. Cytoprotective Preconditioning of Osteoblast-Like Cells with N-AcetylL-Cysteine for Bone Regeneration in Cell Therapy. Int. J. Mol. Sci. 2019, 20, 5199. [CrossRef]

47. Kristensen, L.P.; Chen, L.; Nielsen, M.O.; Qanie, D.W.; Kratchmarova, I.; Kassem, M.; Andersen, J.S. Temporal profiling and pulsed SILAC labeling identify novel secreted proteins during ex vivo osteoblast differentiation of human stromal stem cells. Mol. Cell Proteom. 2012, 11, 989-1007. [CrossRef] [PubMed]

48. Foster, L.J.; Zeemann, P.A.; Li, C.; Mann, M.; Jensen, O.N.; Kassem, M. Differential expression profiling of membrane proteins by quantitative proteomics in a human mesenchymal stem cell line undergoing osteoblast differentiation. Stem Cells 2005, 23, 1367-1377. [CrossRef] [PubMed]

49. Granéli, C.; Thorfve, A.; Ruetschi, U.; Brisby, H.; Thomsen, P.; Lindahl, A.; Karlsson, C. Novel markers of osteogenic and adipogenic differentiation of human bone marrow stromal cells identified using a quantitative proteomics approach. Stem Cell Res. 2014, 12, 153-165. [CrossRef] [PubMed]

50. Aasebø, E.; Brenner, A.K.; Hernandez-Valladares, M.; Birkeland, E.; Berven, F.S.; Selheim, F.; Bruserud, Ø. Proteomic Comparison of Bone Marrow Derived Osteoblasts and Mesenchymal Stem Cells. Int. J. Mol. Sci 2021, 22, 5665. [CrossRef]

51. Yuan, Z.; Li, Q.; Luo, S.; Liu, Z.; Luo, D.; Zhang, B.; Zhang, D.; Rao, P.; Xiao, J. PPAR $\gamma$ and Wnt Signaling in Adipogenic and Osteogenic Differentiation of Mesenchymal Stem Cells. Curr Stem Cell Res. 2016, 11, 216-225. [CrossRef]

52. Parisuthiman, D.; Mochida, Y.; Duarte, W.R.; Yamauchi, M. Biglycan modulates osteoblast differentiation and matrix mineralization. J. Bone Miner. Res. 2005, 20, 1878-1886. [CrossRef] [PubMed]

53. Chen, X.-D.; Fisher, L.W.; Robey, P.G.; Young, M.F. The small leucine-rich proteoglycan biglycan modulates BMP-4-induced osteoblast differentiation. FASEB J. 2004, 18, 948-958. [CrossRef] [PubMed] 
54. Ye, Y.; Hu, W.; Guo, F.; Zhang, W.; Wang, J.; Chen, A. Glycosaminoglycan chains of biglycan promote bone morphogenetic protein-4-induced osteoblast differentiation. Int. J. Mol. Med. 2012, 30, 1075-1080. [CrossRef]

55. Li, X.; Pennisi, A.; Yaccoby, S. Role of decorin in the antimyeloma effects of osteoblasts. Blood 2008, 112, 159-168. [CrossRef]

56. Liu, L.; Pathak, J.L.; Zhu, Y.-Q.; Bureik, M. Comparison of cytochrome P450 expression in four different human osteoblast models. Biol. Chem. 2017, 398, 1327-1334. [CrossRef]

57. van Driel, M.; Koedam, M.; Buurman, C.J.; Hewison, M.; Chiba, H.; Uitterlinden, A.G.; Pols, H.A.; van Leeuwen, J.P. Evidence for auto/paracrine actions of vitamin D in bone: 1alpha-hydroxylase expression and activity in human bone cells. FASEB J. 2006, 20, 2417-2419. [CrossRef] [PubMed]

58. Moena, D.; Merino, P.; Lian, J.B.; Stein, G.S.; Stein, J.L.; Montecino, M. Switches in histone modifications epigenetically control vitamin D3-dependent transcriptional upregulation of the CYP24A1 gene in osteoblastic cells. J. Cell Physiol. 2020, 235, 5328-5339. [CrossRef]

59. Segal, E.; Friedman, N.; Koller, D.; Regev, A. A module map showing conditional activity of expression modules in cancer. Nat. Genet. 2004, 36, 1090-1098. [CrossRef]

60. Volk, S.W.; Shah, S.R.; Cohen, A.J.; Wang, Y.; Brisson, B.K.; Vogel, L.K.; Hankenson, K.D.; Adams, S.L. Type III collagen regulates osteoblastogenesis and the quantity of trabecular bone. Calcif. Tissue Int. 2014, 94, 621-631. [CrossRef]

61. Kumar, R.; Haugen, J.D. Human and rat osteoblast-like cells express stathmin, a growth-regulatory protein. Biochem. Biophys. Res. Commun. 1994, 201, 861-865. [CrossRef]

62. Liu, H.; Zhang, R.; Ko, S.-Y.; Oyajobi, B.O.; Papasian, C.J.; Deng, H.-W.; Zhang, S.; Zhao, M. Microtubule assembly affects bone mass by regulating both osteoblast and osteoclast functions: Stathmin deficiency produces an osteopenic phenotype in mice. $J$. Bone Mineral. Res. 2011, 26, 2052-2067. [CrossRef] [PubMed]

63. Kuijjer, M.L.; Rydbeck, H.; Kresse, S.H.; Buddingh, E.P.; Lid, A.B.; Roelofs, H.; Bürger, H.; Myklebost, O.; Hogendoorn, P.C.W.; Meza-Zepeda, L.A.; et al. Identification of osteosarcoma driver genes by integrative analysis of copy number and gene expression data. Genes Chromosomes Cancer 2012, 51, 696-706. [CrossRef]

64. Yang, C.; Pring, M.; Wear, M.A.; Huang, M.; Cooper, J.A.; Svitkina, T.M.; Zigmond, S.H. Mammalian CARMIL inhibits actin filament capping by capping protein. Dev. Cell 2005, 9, 209-221. [CrossRef]

65. Myllyharju, J.; Kivirikko, K.I. Collagens, modifying enzymes and their mutations in humans, flies and worms. Trends Genet. 2004, 20, 33-43. [CrossRef] [PubMed]

66. Li, Q.; Shen, Z.; Wu, Z.; Shen, Y.; Deng, H.; Zhou, C.; Liu, H. High P4HA1 expression is an independent prognostic factor for poor overall survival and recurrent-free survival in head and neck squamous cell carcinoma. J. Clin. Lab. Anal. 2020, 34, e23107. [CrossRef]

67. Eriksson, J.; Le Joncour, V.; Jahkola, T.; Juteau, S.; Laakkonen, P.; Saksela, O.; Hölttä, E. Prolyl 4-hydroxylase subunit alpha 1 (P4HA1) is a biomarker of poor prognosis in primary melanomas, and its depletion inhibits melanoma cell invasion and disrupts tumor blood vessel walls. Mol. Oncol. 2020, 14, 742-762. [CrossRef]

68. Rappaport, N.; Nativ, N.; Stelzer, G.; Twik, M.; Guan-Golan, Y.; Stein, T.I.; Bahir, I.; Belinky, F.; Morrey, C.P.; Safran, M.; et al. MalaCards: An integrated compendium for diseases and their annotation. Database 2013, 2013, bat018. [CrossRef] [PubMed]

69. Rossi, V.; Lee, B.; Marom, R. Osteogenesis imperfecta: Advancements in genetics and treatment. Curr. Opin. Pediatr. 2019, 31, 708-715. [CrossRef]

70. Chen, L.; Shi, K.; Frary, C.E.; Ditzel, N.; Hu, H.; Qiu, W.; Kassem, M. Inhibiting actin depolymerization enhances osteoblast differentiation and bone formation in human stromal stem cells. Stem Cell Res. 2015, 15, 281-289. [CrossRef] [PubMed]

71. Prudovsky, I.; Anunciado-Koza, R.P.; Jacobs, C.G.; Kacer, D.; Siviski, M.E.; Koza, R.A. Mesoderm-specific transcript localization in the ER and ER-lipid droplet interface supports a role in adipocyte hypertrophy. J. Cell Biochem. 2018, 119, 2636-2645. [CrossRef]

72. Kadota, Y.; Yanagawa, M.; Nakaya, T.; Kawakami, T.; Sato, M.; Suzuki, S. Gene expression of mesoderm-specific transcript is upregulated as preadipocytes differentiate to adipocytes in vitro. J. Physiol. Sci. 2012, 62, 403-411. [CrossRef] [PubMed]

73. Shan, T.; Liu, W.; Kuang, S. Fatty acid binding protein 4 expression marks a population of adipocyte progenitors in white and brown adipose tissues. FASEB J. 2013, 27, 277-287. [CrossRef] [PubMed]

74. Hng, C.H.; Camp, E.; Anderson, P.; Breen, J.; Zannettino, A.; Gronthos, S. HOPX regulates bone marrow-derived mesenchymal stromal cell fate determination via suppression of adipogenic gene pathways. Sci. Rep. 2020, 10, 11345. [CrossRef] [PubMed]

75. Gamucci, O.; Lisi, S.; Scabia, G.; Marchi, M.; Piaggi, P.; Duranti, E.; Virdis, A.; Pinchera, A.; Santini, F.; Maffei, M. Haptoglobin deficiency determines changes in adipocyte size and adipogenesis. Adipocyte 2012, 1, 142-183. [CrossRef] [PubMed]

76. Christiaens, V.; Van Hul, M.; Lijnen, H.R.; Scroyen, I. CD36 promotes adipocyte differentiation and adipogenesis. Biochim. Biophys. Acta 2012, 1820, 949-956. [CrossRef]

77. Do Nascimento, F.V.; Piccoli, V.; Beer, M.A.; von Frankenberg, A.D.; Crispim, D.; Gerchman, F. Association of HSD11B1 polymorphic variants and adipose tissue gene expression with metabolic syndrome, obesity and type 2 diabetes mellitus: A systematic review. Diabetol. Metab. Syndr. 2015, 7, 38. [CrossRef]

78. Pizzinat, N.; Marti, L.; Remaury, A.; Leger, F.; Langin, D.; Lafontan, M.; Carpéné, C.; Parini, A. High expression of monoamine oxidases in human white adipose tissue: Evidence for their involvement in noradrenaline clearance. Biochem. Pharm. 1999, 58, 1735-1742. [CrossRef]

79. Rodriguez-Cuenca, S.; Whyte, L.; Hagen, R.; Vidal-Puig, A.; Fuller, M. Stearoyl-CoA Desaturase 1 Is a Key Determinant of Membrane Lipid Composition in 3T3-L1 Adipocytes. PLoS ONE 2016, 11, e0162047. [CrossRef] 
80. Ellis, J.M.; Li, L.O.; Wu, P.-C.; Koves, T.R.; Ilkayeva, O.; Stevens, R.D.; Watkins, S.M.; Muoio, D.M.; Coleman, R.A. Adipose acyl-CoA synthetase- 1 directs fatty acids toward beta-oxidation and is required for cold thermogenesis. Cell Metab. 2010, 12, 53-64. [CrossRef]

81. Himmelfarb, M.; Klopocki, E.; Grube, S.; Staub, E.; Klaman, I.; Hinzmann, B.; Kristiansen, G.; Rosenthal, A.; Dürst, M.; Dahl, E. ITIH5, a novel member of the inter-alpha-trypsin inhibitor heavy chain family is downregulated in breast cancer. Cancer Lett. 2004, 204, 69-77. [CrossRef]

82. Taira, K.; Umikawa, M.; Takei, K.; Myagmar, B.E.; Shinzato, M.; Machida, N.; Uezato, H.; Nonaka, S.; Kariya, K. The Traf2and Nck-interacting kinase as a putative effector of Rap2 to regulate actin cytoskeleton. J. Biol. Chem. 2004, 279, 49488-49496. [CrossRef] [PubMed]

83. Decker, M.; Adamska, M.; Cronin, A.; Di Giallonardo, F.; Burgener, J.; Marowsky, A.; Falck, J.R.; Morisseau, C.; Hammock, B.D.; Gruzdev, A.; et al. EH3 (ABHD9): The first member of a new epoxide hydrolase family with high activity for fatty acid epoxides. J. Lipid Res. 2012, 53, 2038-2045. [CrossRef] [PubMed]

84. Gautheron, J.; Jéru, I. The Multifaceted Role of Epoxide Hydrolases in Human Health and Disease. Int. J. Mol. Sci. 2020, 22, 13. [CrossRef] [PubMed]

85. Smyth, S.S.; Sciorra, V.A.; Sigal, Y.J.; Pamuklar, Z.; Wang, Z.; Xu, Y.; Prestwich, G.D.; Morris, A.J. Lipid phosphate phosphatases regulate lysophosphatidic acid production and signaling in platelets: Studies using chemical inhibitors of lipid phosphate phosphatase activity. J. Biol. Chem. 2003, 278, 43214-43223. [CrossRef] [PubMed]

86. Zhao, Y.; Usatyuk, P.V.; Cummings, R.; Saatian, B.; He, D.; Watkins, T.; Morris, A.; Spannhake, E.W.; Brindley, D.N.; Natarajan, V. Lipid phosphate phosphatase-1 regulates lysophosphatidic acid-induced calcium release, NF-kappaB activation and interleukin-8 secretion in human bronchial epithelial cells. Biochem. J. 2005, 385, 493-502. [CrossRef]

87. Stenderup, K.; Justesen, J.; Clausen, C.; Kassem, M. Aging is associated with decreased maximal life span and accelerated senescence of bone marrow stromal cells. Bone 2003, 33, 919-926. [CrossRef]

88. Gemoll, T.; Epping, F.; Heinrich, L.; Fritzsche, B.; Roblick, U.J.; Szymczak, S.; Hartwig, S.; Depping, R.; Bruch, H.-P.; Thorns, C.; et al. Increased cathepsin D protein expression is a biomarker for osteosarcomas, pulmonary metastases and other bone malignancies. Oncotarget 2015, 6, 16517-16526. [CrossRef]

89. Manza, L.L.; Stamer, S.L.; Ham, A.-J.L.; Codreanu, S.G.; Liebler, D.C. Sample preparation and digestion for proteomic analyses using spin filters. Proteomics 2005, 5, 1742-1745. [CrossRef]

90. Demichev, V.; Messner, C.B.; Vernardis, S.I.; Lilley, K.S.; Ralser, M. DIA-NN: Neural networks and interference correction enable deep proteome coverage in high throughput. Nat. Methods 2020, 17, 41-44. [CrossRef]

91. The UniProt Consortium. UniProt: A worldwide hub of protein knowledge. Nucleic Acids Res. 2018, 47, D506-D515. [CrossRef]

92. Cox, J.; Hein, M.Y.; Luber, C.A.; Paron, I.; Nagaraj, N.; Mann, M. Accurate Proteome-wide Label-free Quantification by Delayed Normalization and Maximal Peptide Ratio Extraction, Termed MaxLFQ. Mol. Cell. Proteom. 2014, 13, 2513-2526. [CrossRef]

93. Deutsch, E.W.; Csordas, A.; Sun, Z.; Jarnuczak, A.; Perez-Riverol, Y.; Ternent, T.; Campbell, D.S.; Bernal-Llinares, M.; Okuda, S.; Kawano, S.; et al. The ProteomeXchange consortium in 2017: Supporting the cultural change in proteomics public data deposition. Nucleic Acids Res. 2017, 45, D1100-D1106. [CrossRef] [PubMed]

94. Perez-Riverol, Y.; Csordas, A.; Bai, J.; Bernal-Llinares, M.; Hewapathirana, S.; Kundu, D.J.; Inuganti, A.; Griss, J.; Mayer, G.; Eisenacher, M.; et al. The PRIDE database and related tools and resources in 2019: Improving support for quantification data. Nucleic Acids Res. 2019, 47, D442-D450. [CrossRef] [PubMed]

95. R Development Core Team. R: A Language and Environment for Statistical Computing; R foundation for Statistical Computing: Vienna, Austria, 2021.

96. Zhang, X.; Smits, A.H.; van Tilburg, G.B.; Ovaa, H.; Huber, W.; Vermeulen, M. Proteome-wide identification of ubiquitin interactions using UbIA-MS. Nat. Protoc. 2018, 13, 530-550. [CrossRef]

97. Huber, W.; von Heydebreck, A.; Sültmann, H.; Poustka, A.; Vingron, M. Variance stabilization applied to microarray data calibration and to the quantification of differential expression. Bioinformatics 2002, 18, S96-S104. [CrossRef]

98. Lazar, C.; Gatto, L.; Ferro, M.; Bruley, C.; Burger, T. Accounting for the Multiple Natures of Missing Values in Label-Free Quantitative Proteomics Data Sets to Compare Imputation Strategies. J. Proteome Res. 2016, 15, 1116-1125. [CrossRef] [PubMed]

99. Akhmedov, M.; Martinelli, A.; Geiger, R.; Kwee, I. Omics Playground: A comprehensive self-service platform for visualization, analytics and exploration of Big Omics Data. NAR Genom. Bioinform. 2020, 2, lqz019. [CrossRef] [PubMed]

100. Wickham, H. ggplot2: Elegant Graphics for Data Analysis; Springer: New York, NY, USA, 2016.

101. Charrad, M.; Ghazzali, N.; Boiteau, V.; Niknafs, A. NbClust: An R Package for Determining the Relevant Number of Clusters in a Data Set. J. Stat. Softw. 2014, 61, 36. [CrossRef]

102. Fisher, R.A. On the Interpretation of $\chi 2$ from Contingency Tables, and the Calculation of P. J. R. Stat. Soc. 1922, 85, 87-94. [CrossRef]

103. Korotkevich, G.; Sukhov, V.; Budin, N.; Shpak, B.; Artyomov, M.N.; Sergushichev, A. Fast gene set enrichment analysis. bioRxiv 2021, 060012. [CrossRef]

104. Hänzelmann, S.; Castelo, R.; Guinney, J. GSVA: Gene set variation analysis for microarray and RNA-Seq data. BMC Bioinform. 2013, 14, 7. [CrossRef] [PubMed]

105. Benjamini, Y.; Hochberg, Y. Controlling the False Discovery Rate: A Practical and Powerful Approach to Multiple Testing. J. R. Stat. Soc. Ser. B Methodol. 1995, 57, 289-300. [CrossRef] 
106. Heberle, H.; Meirelles, G.V.; da Silva, F.R.; Telles, G.P.; Minghim, R. InteractiVenn: A web-based tool for the analysis of sets through Venn diagrams. BMC Bioinform. 2015, 16, 169. [CrossRef] [PubMed]

107. Mi, H.; Ebert, D.; Muruganujan, A.; Mills, C.; Albou, L.-P.; Mushayamaha, T.; Thomas, P.D. PANTHER version 16: A revised family classification, tree-based classification tool, enhancer regions and extensive API. Nucleic Acids Res. 2020, 49, D394-D403. [CrossRef] [PubMed] 